\title{
Investigaçōes limnológicas e ictiológicas em Curuá-Una, a primeira represa hidrelétrica na Amazônia Central.
}

\author{
Wolfgang J. Junk ( ${ }^{1}$ ) \\ Bárbara A. Robertson ( ${ }^{2}$ ) \\ Assad José Darwich ${ }^{2}$ ) \\ Ivanzir Vieira ${ }^{(3)}$
}

\section{Resumo}

No presente trabalho, são apresentados os resultados limnológicos elaborados durante o período de abril e maio de 1978, em Curuá-Una, a primeirá represa hidrelétrica da bacia Amazônica. Foram estudadas as condiçōes hidroquímicas, as macrófitas aquáticas, o zooplâncton (Cladocera), e a ictiofauna. A água dos afluentes da represa, de um modo geral, é extremamente pobre em sais minerais. Mesmo assim, observaram-se nítidas diferenças químicas entre os afluentes principais. A reduçāo no teor de oxigênio, dentro da represa, foi bem pronunciada. Grandes quantidades de macrófitas aquáticas flutuantes ocorreram na represa, sendo que as principais espécies foram: Eichhornia crassipes, Scirpus cubensis, Pistia stratiotes e Paspalum repens. A abundância das plantas e sua ocorrência mostram nítidas relaçōes com as condiçōes hidroquímicas. As 34 espécies de Cladocera, representantes de 6 familias, foram identificadas. O número de indivíduos, no entanto, foi relativamente baixo. Três espécies, Bosminopsis deitersi, Ceriodaphnia cornuta e Ceriodaphnia reticulata representaram entre $53-99 \%$ dos espécimens coletados. Sessenta e duas espécies de peixes, pertencendo a 14 famllias, foram coletadas. Observou-se uma preferência de algumas espécies pela área do reservatório, enquanto outras foram encontradas principalmente acima ou abaixo da represa. A freqüência de piranhas foi duas vezes maior na represa, do que ros locais acima ou abaixo da mesma.

\section{INTRODUÇÃO}

A energia hidrelétrica desempenha importante papel no abastecimento energético do Brasil. Em 1976, as hidrelétricas geraram 17.657 MW, correspondendo a $83,9 \%$ da energia elétrica total do país. Para 1977 estimou-se uma quantidade de 19.198 MW, correspondendo a $84,8 \%$ da energia elétrica total, (comunicação pessoal do Dr. Melquíades Pinto Paiva,
Consultor da Diretoria de Coordenação da ELETROBRÁS). Na revista Construção Pesada, de fevereiro de 1976, há uma lista composta de 231 represas hidrelétricas, das quais 149 estavam em funcionamento e $82 \mathrm{em}$ fase de construção ou planejamento.

Logicamente, essas construções até agora, concentram-se na região sul do país, altamente industrializada. O imenso sistema fluvial do Amazonas ainda não foi utilizado para a produção de energia elétrica, em virtude da baixa densidade populacional, como também da escassez de indústrias de alta potência, que resulta em um uso limitado de energia.

Todavia, considerando os planos do governo brasileiro para o desenvolvimento da região amazônica, as companhias elétricas avaliaram o potencial dos afluentes do rio Amazonas, para garantir, a longo prazo, o abastecimento energético dos grandes projetos agropecuários e industriais planejados para essa região. As primeiras pequenas hidrelétricas que começaram a funcionar em 1977, foram as de CuruáUna, próximo a Santarém, Pará, e Paredão, ao norte de Belém. Está em fase de construção a represa de Tucuruí, no rio Tocantins, uma das maiores do país. Estão em fase de planejamento as represas de Balbina, no rio Uatumã, perto de Manaus, e Samuel, no rio Jamari, perto de Porto Velho.

Enquanto, por um lado, o planejamento e a construção das represas acima citadas, programadas para a região amazônica, se encontram em fase bastante adiantada, por outro as informações sobre possíveis influências ao meio

(1) - Convênio Instituto Nacional de Pesquisas da Amazônia (INPA), Manaus e Instituto Max-Planck para Limnologia, Depto. de Ecologia Tropical, Plön - Alemanina.

(2) - Instituto Nacional de Pesquisas da Amazônia, Manaus.

(3) - Universidade Federal de Juiz de Fora, MG. 
ambiente devem ser consideradas insuficientes.

Existe uma série de dados sobre a limnologia de águas amazônicas: (Sioli, 1957, 1965, 1967, 1968, 1976; Schmidt, 1972, 1973 a, b, c, 1976; Reiss, 1976 a,b, 1977; Junk 1970, 1973, 1975; Junk \& Furch, 1980; Irmler, 1975, 1976; Brandcrff, 1977; Marlier, 1965, 1967, 1969; Braum, 1952, e outros). Resta averiguar até que ponto os resultados dessas investigações podem ser transferidos às condições específicas de represas, que além de serem artificiais, serão os únicos corpos de água na Bacia Amazônica com caráter permanente de lago.

Estudos sobre o lago Brokopondo no Suriname, a primeira represa hidrelétrica grande na América do Sul Tropical, indicaram sérios problemas ecológicos, que permaneceram após sua construção (Leentvaar, 1966, 1967, 1971, 1973), focalizando suficientemente a necessidade de estudos adicionais detalhados. Neste contexto, deve ser mencionado, por exemplo, o desenvolvimento incontrolado de macrófitas aquáticas em grande escala. Considerando o fato de que as espécies endêmicas à Amazônia, tais como Pistia stratiotes. Eichhornia crassipes, Salvinia auriculata e Ceratopteris pteridoides, pertencem às ervas daninnas aquáticas mais problemáticas em águas tropicais, estudos limnológicos detalhados em represas amazônicas recebem uma importância supra-regional.

O presente trabalho descreve a situação limnológica de Curuá-Una, a primeira represa hidrelétrica da bacia Amazônica, após o término das obras. Os resultados baseiam-se em dados coletados em abril e maio de 1978. No entanto, é prevista a continuação de estudos intensivos durante um período de vários anos para abranger as mudanças do ecossistema, qualitativa e quantitativamente, até sua estabilização.

\section{DESCRIÇÃo DA ÁREA GEOLOGIA}

A represa de Curuá-Una está situada a 80 $\mathrm{km}$ a sudeste de Santarém, Pará, na região dos sedimentos terciários da formaçăo Barreiras. Recebe suas águas pelo rio Curuá-Una e seus afluentes, rios Moju, Mujuí dos Campos e Poraquê. Embora a bacia de captura dos afluentes se encontre totalmente na Formação Barreiras, geoquimicamente pobre em extremo, o rio Curuá-Una atinge no seu curso superior áreas geoquimicamente mais ricas, assim como o Carbonífero da série Itaituba (Hartt, 1874), agora chamado de Grupo Tapajós (Santos et al., 1975), e Conglomerados precambrianos, granitos e gneisses (BRASIL, 1975, 1976) (Fig. 1).

\section{CLIMA}

Conforme BRASIL (1972), a precipitação anual em Santarém é de $2.096 \mathrm{~mm}$ com uma época chuvosa bem acentuada no período de fevereiro a maio, e uma epoca seca abrangendo

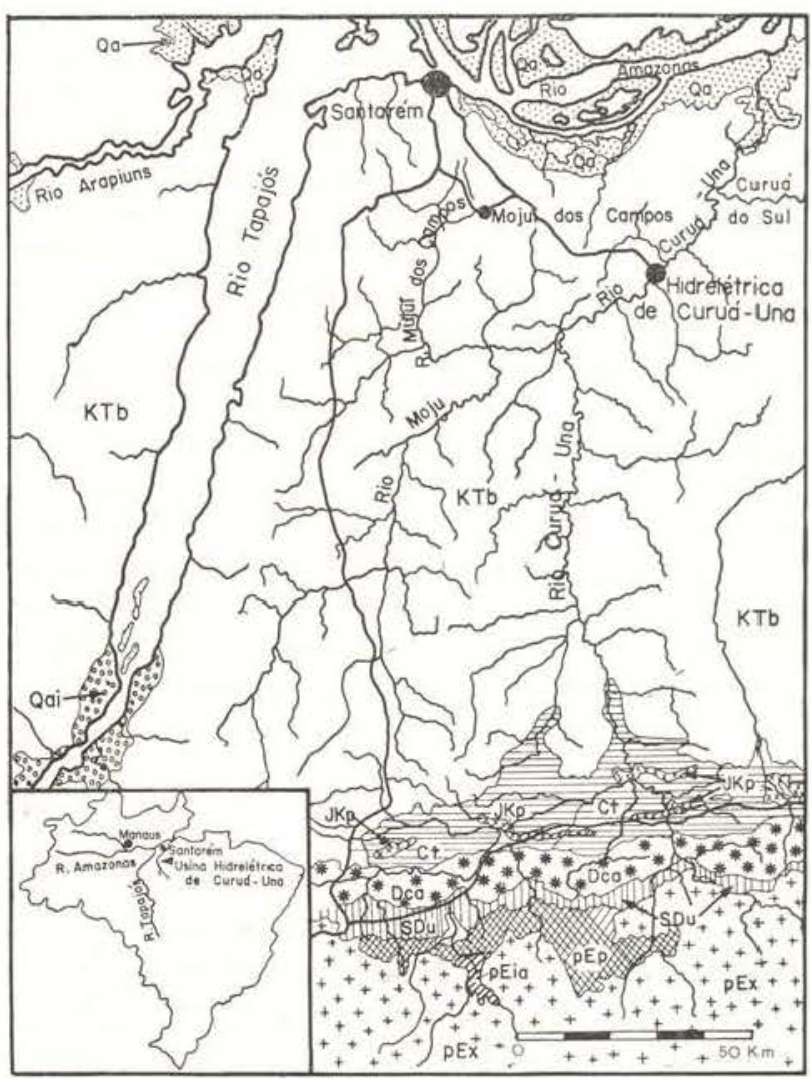

[200, Cretaceo: $\mathrm{E}$ Ct-Grupo Tapajós, Carbonifero: \# DCa-Formaçäo Curua, Devoniano Superior: IIIII)SDu-Grupo Urupadi, Siluro-Devoniano, DEP-Formaçáo Prosperança, Pré-Cambriano Superior: IIIAA pEia - Grupo Uatumā, Pré-Cambriano Superior, E+ $t^{+}+D E x$ - Complexo xingu. Pré-Cambriano inferior a Médio: $\square$ kTb-Formaç̄o. Barreiras, Cretáceo - Terciório. (Rodam, 1975, 1976

Fig. 1 - Mapa geológico da bacia hidrográfica do rio Curcá-Una. 
os meses de agosto a novembro. A evaporação total é de $631 \mathrm{~mm}$ e a umidade relativa do ar sempre acima de $75 \%$. Conforme Bagnouls \& Gaussen (1963), o clima de Santarém é classificado na categoria bioclimática de "clima xeroquimênico" representado pela sub-regiăo subtermaxérica (BRASIL, 1976). Perto de Santarém, aparecem grandes áreas de cerrado, no entanto a região da represa é coberta por uma densa floresta pluvial tropical.

\section{DADOS GERAIS SOBRE A REPRESA}

Conforme dados da ELETROBRAS, a capacidade de a usina gerar energia hidrelétrica é de $40 \mathrm{MW}$. Quando cheia (quota $68 \mathrm{~m}$ acima do nível do mar), a represa cobre uma área de cerca de $100 \mathrm{~km}^{2}$. É alongada e estreita, com uma largura máxima de aproximadamente $3 \mathrm{~km}$. A Figura 2 apresenta detalhes da mesma atẻ $78,5 \mathrm{~km}$ acima da barragem. Todavia, a influência do represamento estende-se além desse ponto. A profundidade máxima perto da barragem é de cerca de $17 \mathrm{~m}$, o volume total de 500 milhōes de metros cúbicos. A profundidade média, na quota de $68 \mathrm{~m}$, é de $5,85 \mathrm{~m}$. Em abril, 1978, com uma vazão média do rio Curuá-Una de $17.100 .000 \mathrm{~m}^{3}$, e um volume médio de 498.630.000 $\mathrm{m}^{3}$ (quota média $67,40 \mathrm{~m}$ ), calcula-se um período teórico de retenção da água na represa de 29,1 dias.

Como a vegetação não foi removida antes do fechamento da barragem, as áreas adjacentes ao antigo leito do rio, estão cobertas com árvores mortas em decomposição.

A figura 3 mostra as mudanças de nível de água antes, durante, e após a construção da barragem.

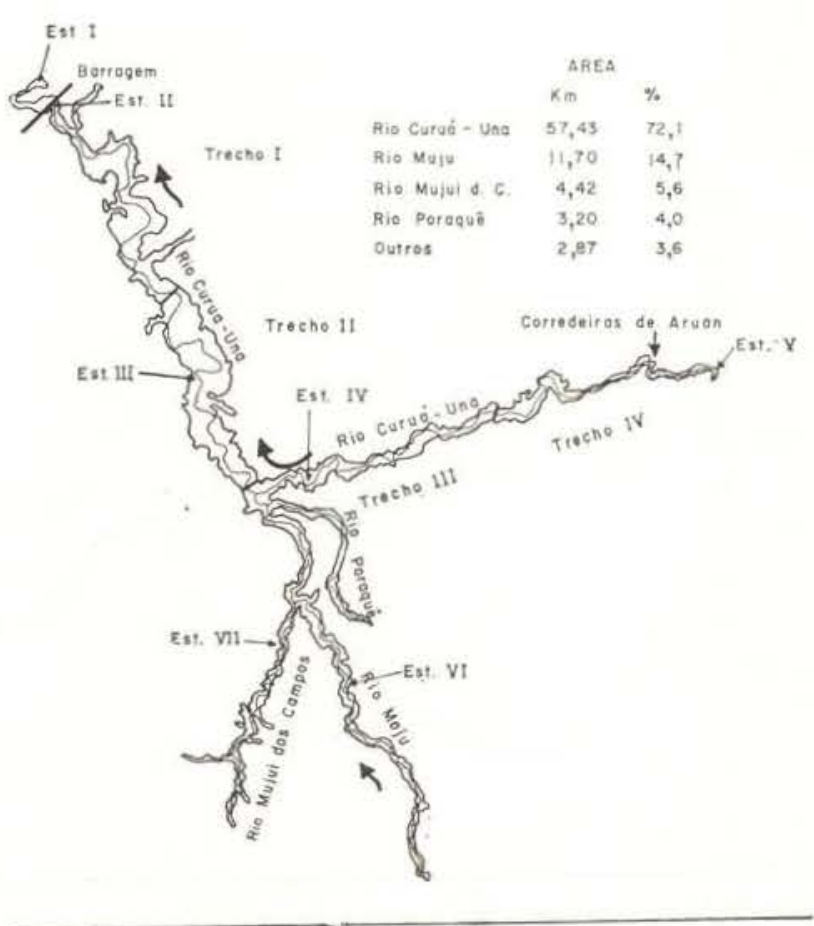

Fig. 2 - Mapa geográfico da represa de Curuá-Una com o antigo leito do rio e as estaçōes de amostragem.

A colonização humana da área é, até agora, pequena, com tendência a aumentar. No curso superior do rio Mujuí dos Campos, acima da área infiuenciada pelo represamento, encontra-se uma agrovila com cerca de 1.000 habitantes. Esta área sofre poluição por meio de esgotos domésticos e agropecuários (fermentação de malva e lavagem das fibras).

\section{MATERIAL E MÉTODOS}

PARÂMETROS FÍSICO-QUÍMICOS

Para análise químiica da água foram escoIhidos os seguintes locais de coleta (Fig. 2).

\begin{tabular}{cll}
\hline No da estação & \multicolumn{1}{c}{ Local de coleta } & Profundidade de amostragem \\
II & $4 \mathrm{~km}$ abaixo da barragem & Superfície \\
III & $\mathrm{Km} 30$ rio Curuá-Una & $0,2,4,8 \mathrm{~m}$ e fundo \\
IV & $\mathrm{Km} 45$ rio Curuá-Una & $0,2,4,8 \mathrm{~m}$ e fundo \\
V & $\mathrm{Km} 80$ rio Curuá-Una & $0,2,4,8 \mathrm{~m}$ e fundo \\
VI & $\mathrm{Km} 25$ rio Moju & $0,2,4,8 \mathrm{~m}$ e fundo \\
VII & $\mathrm{Km} \mathrm{20}$ rio Mujuí dos Campos & $0,2,4,8 \mathrm{~m}$ e fundo \\
\hline
\end{tabular}

(") A profundidade máxima é indicada na Fig. 4. 


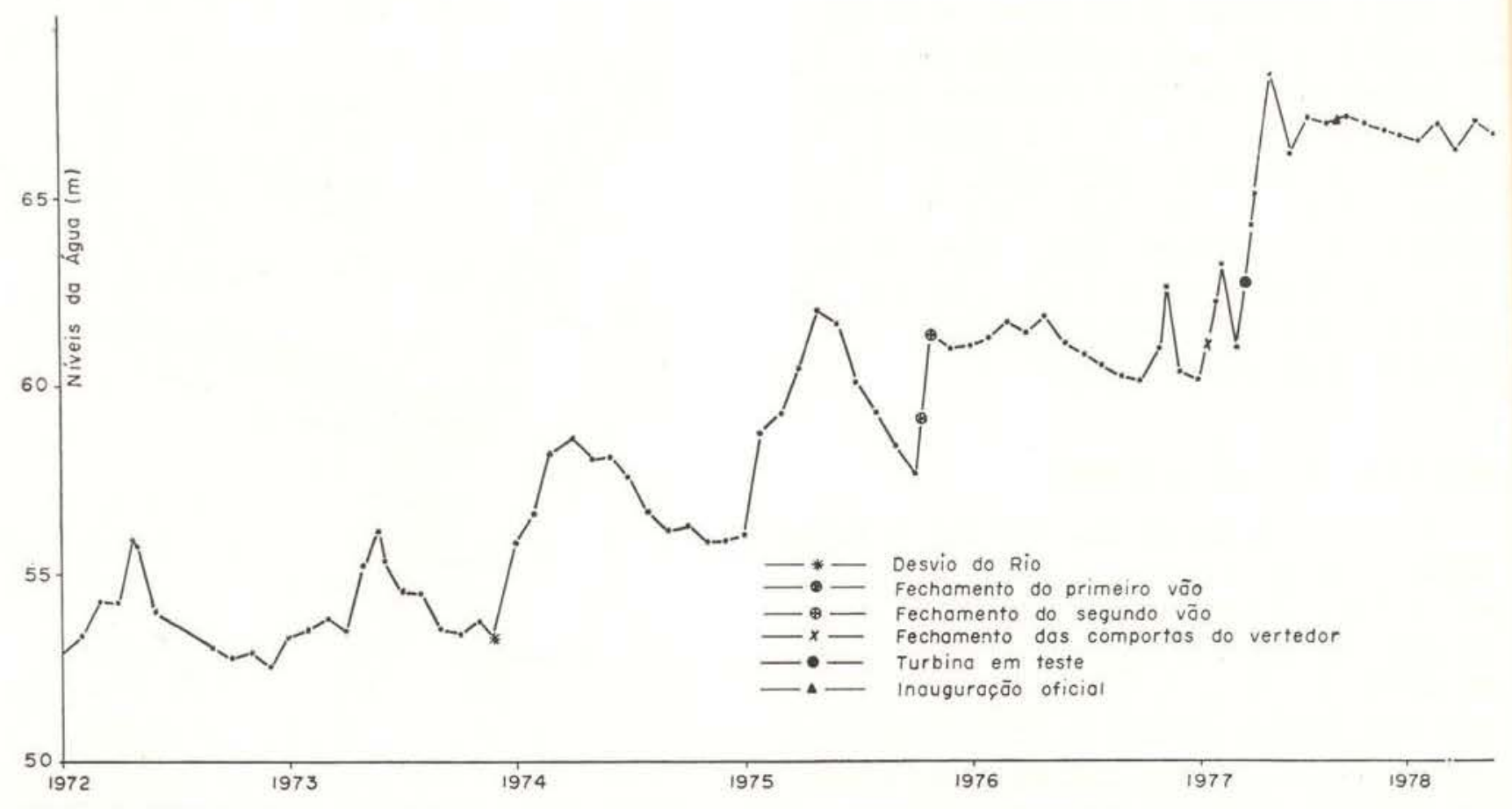

Fig. 3 - Niveis de água do rio Curuá-Una antes e após n represamento. (Dados cedidos pela CELPA). Os dados se referem ao primeiro dia de cada mês. Flutıações drásticas são indicadas adicionalmente.

O oxigênio foi determinado em todas as estações, em cada metro, com exceção da estação I. Nesta, foram tomadas amostras somente na superfície em virtude das fortes turbulências desta região, que provocaram uma mistura completa da coluna d'água, que nesta época tinha uma profundidade máxima de $9 \mathrm{~m}$. As amostras foram coletadas com um coletor de Ruttner. A temperatura, transparência, pH, condutiviaade elétrica, oxigênio, $\mathrm{CO}_{2}$ total, e alcalinidade, foram determinados no campo, ou num pequeno laboratório provisório, na represa. Usou-se para determinação de temperatura um termômetro com sensibilidade de $0,1^{\circ} \mathrm{C}$, para a transparência, um disco de Secchi de $30 \mathrm{~cm}$ de diâmetro, e para $\mathrm{pH}$, e condutividade elétrica, os medidores de campo do WTW. O oxigênio foi determinado através do método Winkler modificado pela azida sódica (Golterman et al., 1978). $\mathrm{CO}_{2}$ total foi determinado por titulação com solução $0,01 \mathrm{n} \mathrm{NaOH}$, usando fenolftaleina como indicador, e depois com solução $0,01 \mathrm{HCl}$, usando como indicador metil laranja.

Um litro de água de cada amostra foi congelado em frascos de polietileno para análises adicionais em Manaus e Piracicaba. $\mathrm{Em}$ Manaus, foram determinados $\mathrm{Si}, \mathrm{P}$ tot. $\mathrm{e}$ $P$ diss. pelo método de Strickland \& Parson (1968), dando a diferença entre ambos os valores de P-particulado. A determinação de $\mathrm{Na}$, $\mathrm{K}, \mathrm{Ca}, \mathrm{Mg}$, e $\mathrm{Fe}$, foi realizada no laboratório do CENA em Piracicaba usando-se um espectrofotômetro de absorção atômica marca Pérkin-Elmer Modelo 306 . Não foi possível determinar $\mathrm{N}$ em suas diferentes composições por causa de problemas metodológicos.

\section{MACRÓFITAS AQUÁTICAS}

O desenvolvimento das macrófitas aquáticas foi estudado através de fotografias aéreas obtidas durante um sobrevôo de 2 horas a uma altura de 300 metros. Para a valorização, foi usada uma escala de sete diferentes graus de cobertura: I $=$ inexistente; II $=<5 \%$; III = $5-20 \%$; IV $=21-40 \% \mathrm{~V}=41-60 \%$; $\mathrm{VI}=61-80 \% ; \mathrm{VII}=81-100 \%$.

A classificação e a determinação da distribuição espacial foram realizadas por meio de avaliação e transferidas para o mapa. Depois, as áreas foram planimetradas e recalculadas 
em quilômetros quadrados. A margem da represa foi determinada na quota de $67 \mathrm{~m}$ porque o nívei de água em maio de 1978 era de $67,61 \mathrm{~m}$.

A valorização das fotografias aéreas foi complementada com observações de barco. A determinação da distribuição das diferentes espécies foi realizada exclusivamente de barco, porque a qualidade das fotos aéreas não permitiu uma análise mais detalhada.

\section{ZOOFLÂNCTON}

As coletas de zooplâncton foram realizadas em intervalos de $1 \mathrm{~m}$, em toda coluna d'água, juntamente com as coletas de água para análise da concentração de oxigênio. Para a coleta de amostras quantitativas, utilizou-se uma bomba manual com hidrômetro e uma mangueira acoplada de $3 \mathrm{~cm}$ de diâmetro, dentro da faixa ideal sugerida por Elster (1958). Cinqüenta (50) litros de água, em intervalos de $1 \mathrm{~m}$, foram filtrados através de uma rede de plâncton de $55 \mu \mathrm{m}$. O material foi fixado no campo com formol a $6-7 \%$. Foram estudados principalmente os crustáceos da ordem Cladócera. A contagem total de amostras foi realizada com auxílio de uma lupa binocular Zeiss, de 10 a 40 vezes de aumento. Para a identificaçãơ do material, prepararam-se lâminas semipermanentes em polivinil-lactofenol.

\section{ICTIOFAUNA}

Os locais de coleta correspondem mais ou menos aos locais de amostragem para determinação dos fatores físico-químicos e para a coleta de zooplâncton. Algumas diferenciações explicam-se pela necessidade de locais apropriadcs para colocar o equipamento de pesca: a estação | foi deslocada $16 \mathrm{~km}$ abaixo; não houve amostragem na estação III, faltando este número nas tabelas. Foi coletado também no rio Curuá do Sul, afluente do lado direito do rio Curuá-IJna, abaixo da represa, recebendo esta estação o número VIII.

Nas estações I, V e VIII, nas quais o rio mostra pouco ou nenhum efeito visivel de represamento, as amostragens foram realizadas tanto na água corrente como no igapó marginal. Nas estaçōes II e IV, dentro da represa, esco-
Iherami-se águas abertas com um mínmo de vegetação flutuante e áreas perto da beira, assombreadas com árvores ainda vivas, biótopo comparativo aos lugares marginais nas estações I, V e VIII. Não se fez amostragem no igapó das estações VI e VII.

Utilizaram-se malhadeiras com fio monofilamento de "nylon" branco de $25 \mathrm{~m}$ de comprimento e cerca de $1,30 \mathrm{~m}$ de altura e $15,20$. 30. 40 e $60 \mathrm{~mm}$ entre-nós. Uma série de cinco redes de diferentes tamanhos de malha foi disposta em cada local amostrado, paralelamente umas às outras, separadas por distâncias que variaram de 8 a $15 \mathrm{~m}$, mantidas à superfície por flutuadores e, na vertical, pela ação da própria correnteza ou pela fixação dos cabos superiores à vegetação ou varas.

A posição das redes variou, sendo elas colocades em águas correntes paralelamente à correnteza; em águas paradas em ângulo de $90^{\circ} \mathrm{com}$ a margem. As malhas maiores foram dispostas à jusante nos rios e na represa decrescendo sua distância entre-nós à montante. As vistorias foram feitas às $17,20,2,4$ e 6 horas com ajuda de dois pescadores e um técnico.

O pescado capturado foi etiquetado individualmente, pesado e medido a fresco, fixado em formol a $10 \%$, e posteriormente conservado em álcool a $70 \%$.

O materia! coletado foi em parte depositado na coleção do INPA, em parte no Museu de Zoologia da Universidade de São Paulo e também na Universidade Federal de Juiz de Fora, em Minas Gerais.

\section{Resultados}

\section{DADOS FÍSICO-QUÍMICOS}

A transparência da água variou entre $0,6 \mathrm{~m}$ na estaçăo V (entrada do rio Curuá-Una na represa) e 2,6 m nas estações VI e VII (entrada dos afluentes Moju e Mujui dos Campos) mantendo na própria represa, valores entre 1,6 $2,0 \mathrm{~m}$. A temperatura mais baixa foi encontrada na estação $V \operatorname{com} 26,5^{\circ} \mathrm{C}$ sendo os afluentes $1^{\circ} \mathrm{C}$ mais quente. No entanto, temos que considerar que, nas estações VI e VII, a correnteza não era tão pronunciada como no rio 
Curuá-Una na estação $\mathrm{V}$. Na própria represa, a água esquentava gradativamente, atingindo, abaixo da barragem (estação I), $29,0^{\circ} \mathrm{C}$. Não houve uma estratificação térmica pronunciada. $O$ gradiente maior de $1,8^{\circ} \mathrm{C}$ na estaçăo $\mathrm{VI}$ foi provocado pelo aquecimento da própria superfície da água com uma diferença de $1,2^{\circ} \mathrm{C}$ entre 0 e $1 \mathrm{~m}$ de profundidade.
Com exceção do $\mathrm{O}_{2}$, existe, em geral, em todas as estações, uma homogeneidade relativamente grande de quase todos os parâmetros, na direção vertical. Diferenças maiores, por enquanto, mostram-se entre os diferentes pontos de coleta, tanto ao longo do rio CuruáUna quanto entre este rio e seus afluentes (Tab. $1-6)$.

TAB. 1 - Valores de $\mathrm{pH}$ e condutividade elétrica $\mathrm{em} \mu \mathrm{S} \cdot \mathrm{cm}^{-1} / 20^{\circ} \mathrm{C}$, em parênteses, nas diferentes estaçöes da re. presa hidrelétrica de Curuá-Una em abril de 1978.

\begin{tabular}{|c|c|c|c|c|c|c|c|}
\hline Estação & I & II & III & IV & v & VI & VII \\
\hline \multicolumn{8}{|l|}{ Profundidade } \\
\hline 0 & $5,3(17,5)$ & $5,2(19,4)$ & $5,3(21,1)$ & $5.4(28,5)$ & $5,4(26,2)$ & $4,2(11,5)$ & $4,3(10,9)$ \\
\hline 2 & & $5,3(19,4)$ & $5,4(24,4)$ & $5,5(28,0)$ & $5,4 \quad(26,2)$ & $4,1(11,9)$ & $4,2(11,4)$ \\
\hline 4 & & $5,2(19,4)$ & $5,4(23,6)$ & $5,5(28,1)$ & $5,4(27,3)$ & $4,1(11,9)$ & $4,3(10,9)$ \\
\hline 8 & & $5,2(19,8)$ & $5,3(24,7)$ & $5,5(28,4)$ & - & $4,1(11,9)$ & $4,3(10,9)$ \\
\hline Fundo & & $5,2(19,9)$ & $5,1 \quad(18,7)$ & $5.5(28.9)$ & $5,4(27,3)$ & $4,1(11,9)$ & $4,3 \quad(10,9)$ \\
\hline Valor médio & $5,3(17,5)$ & $5.2(19,6)$ & $5,3 \quad(22,4)$ & $5,5(28,4)$ & $5,4(26,8)$ & $4,1(11,8)$ & $4,3(11,0)$ \\
\hline
\end{tabular}

TAB. 2 - Valores de $\mathrm{Na}$ e $\mathrm{K}$, em parênteses, em $\mathrm{mg} / \mathrm{l}$ nas diferentes estaçōes da represa hidrelétrica de Curuá. Una em maio de 1978.

\begin{tabular}{|c|c|c|c|c|c|c|c|}
\hline Estação & I & II & III & IV & v & VI & VII \\
\hline \multirow{2}{*}{\multicolumn{8}{|c|}{ Profundidade }} \\
\hline & & & & & & & \\
\hline 0 & 1,69 & $1,59(0,91)$ & $1,60(0,85)$ & $2,05(1,30)$ & $1,60(1,30)$ & $0.50(0,18)$ & $1,15(0,45)$ \\
\hline 2 & - & $1,62(0,91)$ & $1,81 \quad(1,00)$ & $2,05(1,30)$ & $1,62(1,30)$ & $0,95(0,18)$ & $1,10(0,36)$ \\
\hline 4 & - & $1,69(0,91)$ & $1,81(1,00)$ & $2,15(1,30)$ & $1,62(1,30)$ & $1,05(0,27)$ & $1,15(0,36)$ \\
\hline 8 & - & $1,69(0,91)$ & $1,78(1,00)$ & $2,05(1,30)$ & $\rightarrow$ & $0.95(0,09)$ & $1,15(0,45)$ \\
\hline Fundo & - & $1,69(0,91)$ & $1,45(0,82)$ & $2,15(1,30)$ & $1,60(1,30)$ & $0,90(0,08)$ & $1,15(0,45)$ \\
\hline Valor médio & 1,69 & $1,66(0,91)$ & $1,69(0,93)$ & $2,09(1,30)$ & $1,61(1,30)$ & $0,95(0,16)$ & $1,15(0,41)$ \\
\hline
\end{tabular}

TAB. 3 - Valores de $\mathrm{Ca}$ e $\mathrm{Mg}$, em parênteses, em $\mathrm{mg} / \mathrm{l}$ nas diferentes estações da represa hidrelétrica de Curuá. Una em maio de 1978.

\begin{tabular}{|c|c|c|c|c|c|c|c|}
\hline Estação & $\mathbf{I}$ & II & III & IV & v & VI & VII \\
\hline \multicolumn{8}{|l|}{ Profundidade } \\
\hline 0 & $0,29(0,38)$ & $0.32(0.39)$ & $0,29(0,39)$ & $0,57(0,63)$ & $0,64(0,67)$ & $0,01(0,02)$ & $0.01(0.06)$ \\
\hline 2 & - & $0,32(0,40)$ & $0,43(0,49)$ & $0,57(0.62)$ & $0,64(0,66)$ & $0,01 \quad(0,03)$ & $0,01 \quad(0.06)$ \\
\hline 4 & - & $0.32(0.39)$ & $0,43(0,49)$ & $0,57(0.62)$ & $0,68(0.67)$ & $0,01 \quad(0,03)$ & $0,01(0,06)$ \\
\hline 8 & - & $0,36(0,40)$ & $0,43(0,46)$ & $0,54 \quad(0,62)$ & - & $0,01(0,03)$ & $0,01 \quad(0,06)$ \\
\hline Fundo & - & $0,32(0,39)$ & $0,21 \quad(0,31)$ & $0,57(0,63)$ & $0,64(0,66)$ & $0,01(0.03)$ & $0,01 \quad(0,07)$ \\
\hline Valor médio & $0,29(0,38)$ & $0,33(0,39)$ & $0,36(0,43)$ & $0,56(0,62)$ & $0,65(0,67)$ & $0,01(0,03)$ & $0,01 \quad(0,06)$ \\
\hline
\end{tabular}


TAB. 4 - Valores de $\mathbf{P}$ tot. e P diss., em parênteses, em $\mu \mathrm{g} / \mathrm{I}$ nas diferentes estaçōes da represa hidrelétrica de Curuá-Una em maìo de 1978.

\begin{tabular}{|c|c|c|c|c|c|c|c|c|c|c|c|c|}
\hline Estação & 1 & II & & III & & IV & & v & & VI & & VII \\
\hline \multicolumn{13}{|l|}{ Profundidade } \\
\hline 0 & $16,0 \quad(5,2)$ & $43,4(7,4)$ & 32,0 & $(5,2)$ & 38,0 & $(3,4)$ & 32.0 & $(7,4)$ & 38,0 & $(7,4)$ & 16,0 & $(5,2)$ \\
\hline 2 & - & $27,0 \quad(7,4)$ & 32,0 & $(11,4)$ & 32,0 & $(5,2)$ & - & & 21,2 & $(3,4)$ & 32,0 & $(5,2)$ \\
\hline 4 & - & $32,0 \quad(5,2)$ & 27,0 & $(13,6)$ & 32,0 & $(3,4)$ & - & & 21,2 & $(3,4)$ & 16,0 & $(5,2)$ \\
\hline 8 & - & $32,0 \quad(5,2)$ & 32,0 & $(7,4)$ & 38,0 & $(7,4)$ & - & & - & & 16,0 & $(5,2)$ \\
\hline Fundo & - & $38,0 \quad(5,2)$ & 38,0 & $(7,4)$ & 38,0 & $(7,4)$ & - & & 32,0 & $(3,4)$ & 16,0 & $(3,4)$ \\
\hline Vaier médio & $16,0 \quad(5,2)$ & $34,5(6,1)$ & 32,3 & $(9,0)$ & 35,6 & $(5,4)$ & 32,0 & $(7,4)$ & 28,1 & $(4,4)$ & 19,2 & $(4,8)$ \\
\hline
\end{tabular}

TAB. $\mathrm{s}$ - Valores de Si e Fe, em parênteses, em $\mathrm{mg} / \mathrm{l}$ nas diferentes estações da represa hidrelétrica de CuruáUna (maio de 1978).

\begin{tabular}{|c|c|c|c|c|c|c|c|c|c|c|}
\hline Estação & & I & II & III & IV & v & & VI & & VII \\
\hline \multicolumn{11}{|l|}{ Profundidade } \\
\hline 0 & 1,05 & $(0,1)$ & $1,31 \quad(0,37)$ & $1.21(0,43)$ & $4,43(0,49)$ & $4,52(0,55)$ & 0,14 & $(0,31)$ & 0,14 & $(0,1)$ \\
\hline 2 & - & & $1,57(0,37)$ & $1,08(0,55)$ & $3,37 \quad(0,39)$ & - & 0.12 & $(0,26)$ & 0,15 & $(0.1)$ \\
\hline 4 & - & & $2,30(0,37)$ & $1,57(0,55)$ & $2,05(0,49)$ & - & 0,14 & $(0,26)$ & 0,16 & $(0,1)$ \\
\hline 8 & - & & $1,96(0,31)$ & $1,28(0,61)$ & $3,38(0.61)$ & - & & $(<0,1)^{\circ}$ & 0,19 & $\left(\begin{array}{ll}0 & 1\end{array}\right)$ \\
\hline Fundo & - & & $1,13(0.29)$ & $1,75(0,43)$ & $3,74(0,55)$ & - & 0,12 & $(<0,1)^{*}$ & 0,15 & $(0,1)$ \\
\hline Valor médio & 1,05 & $(0,1)$ & $1,65(0,34)$ & $1,38(0,51)$ & $3.39(0,51)$ & $4,52(0,55)$ & 0.13 & $(0,21)$ & 0.16 & $(0,1)$ \\
\hline
\end{tabular}

(*) - Pora o cálculo do valor médio foi usado o valor 0,1 .

TAB. 6 - Valores de $\mathrm{CO}_{2}$ tot. em $\mathrm{mg} / \mathrm{l}$ e alcalinidade, e m parênteses, em $\mathrm{m}$ val/l nas diferentes estações da represa hidrelétrica de Curuá.Una em abril de 1978.

\begin{tabular}{c|c|r|r|r|r|r|r|r}
\hline Estação & I & II & III & IV & V & VI & VII \\
\hline & & & & & & \\
Profundidade & & & & & & \\
0 & $8,36(0,20)$ & $9,24(0,21)$ & $7,92(0,32)$ & $8,80(0,34)$ & $6,60(0,13)$ & $9,40(0)$ & $8,36(0)$ \\
2 & - & $9,68(0,20)$ & $8,80(0,28)$ & $9.20(0,30)$ & $6,16(0,28)$ & $10,56(0)$ & $8,48(0)$ \\
4 & - & $10,12(0,19)$ & $9,68(0,28)$ & $9,24(0,28)$ & $6,60(0,30)$ & $10,30(0)$ & $8,58(0)$ \\
8 & - & $10,78(0,19)$ & $946(0,27)$ & $9,46(0,28)$ & - & $11,22(0)$ & $6,82(0)$ \\
Fundo & - & $9,68(0,20)$ & $10,12(0,24)$ & $9,24(0,32)$ & $7,04(0,24)$ & $12,10(0)$ & $7,26(0)$ \\
Valor médio & $8,36(0,20)$ & $9,90(0,20)$ & $9,20(0,28)$ & $9,15(0,30)$ & $6,60(0,28)$ & $10,69(0)$ & $7,70(0)$ \\
& & & & & & & \\
\hline
\end{tabular}

A condutividade elétrica mostrou uma quantidade muito baixa de eletrólitos no rio CuruáUna e nos seus afluentes. Porém, o rio CuruáUna apresentou uma condutividade elétrica quase duas e meia vezes mais alta que a dos seus afluentes. A condutividade depois de um leve aumento na estação IV, baixou gradativa- mente chegando, abaixo da barragem, à 17,5 uS. $\mathrm{cm}^{-1} / 20^{\circ} \mathrm{C}$. O pH do rio Curuá-Una era ácido $(5,4)$. Seus afluentes, no entanto, apresentaram valores bem mais baixos, de 4,1 e 4,3 , respectivamente. (Tab. 1).

Em geral, as concentraçōes dos sais minerais são baixas, porém o rio Curuá-Una é mais 
rico em Cations de que os seus afluentes. Isso se mostra especialmente nas concentrações do $\mathrm{Si}$ e dos metais alcalino-terrosos $\mathrm{Ca}$ e $\mathrm{Mg}$, sendo o Ca nos afluentes perto, ou até abaixo, da sensibilidade do método $(0,01 \mathrm{mg} / \mathrm{I})$. (Tab. 3-5). Conseqüentemente, a dureza da água, calculada em graus alemães de dureza, com valores menores do que 1 , é muito baixo. Menos pronunciadas são as diferenças nas concentrações dos metais alcalinos especialmente do sódio (Tab. 2). Dos elementos traços Fe, $\mathrm{Mn}$. Cu e $\mathrm{Zn}$, somente o ferro esteve acima dos limites da sensibilidade do método, de $0,01 \mathrm{mg} / \mathrm{I}$, com exceção da estação VII no rio Mujuí dos Campos (Tab. 5) .

As concentrações do fósforo, tanto no total quanto no fosfato, diferem relativamente pouco, mostrando somente um declive do fósforo particulado atrás da barragem (Tab. 4) .

As diferenças mais pronunciadas ao longo da represa mostram-se nas concentrações de oxigênio. Existiu um declive pronunciado de cerca de $4 \mathrm{mg} / \mathrm{O}_{2} / \mathrm{l}$ na estação $\mathrm{V}$ para menos que $0,5 \mathrm{mg} / \mathrm{l}$ perto da barragem, e um aumento drástico abaixo dela para $6 \mathrm{mg} / \mathrm{l}$. (Fig. 4).
A estratificação foi pouco pronunciada, porém, os valores da superfície eram, em geral, um pouco mais elevados. $\mathrm{H}_{2} \mathrm{~S}$ não foi detectado durante a época estudada. Faltou, inclusive, o cheiro de $\mathrm{H}_{2} \mathrm{~S}$, normalmente presente perto das turbinas na época seca.

\section{MACRÓFITAS AQUÁTICAS}

A tabela 7 indica as espécies de macrófitas aquáticas e semi-aquáticas até agora encontradas na área com referências à distribuiçăo e freqüência das mesmas. Mostra-se claramente. que o centro de desenvolvimento das macrófitas aquáticas está localizado nas áreas influenciadas pelas águas relativamente ricas em nutrientes do rio Curuá-Una. Nas áreas influenciadas pelas águas de orígem da série de Barreiras, somente Syngonanthus anomalus ocorreu em quantidades maiores, flutuando perto da superfície da água. A maioria das espécies săo plantas emersas flutuantes. As espécies que até agora conseguiram colonizar, secundariamente, as comunidades de plantas flutuantes, ou troncos de árvores submersas. são, até o presente, sem importância, tanto em

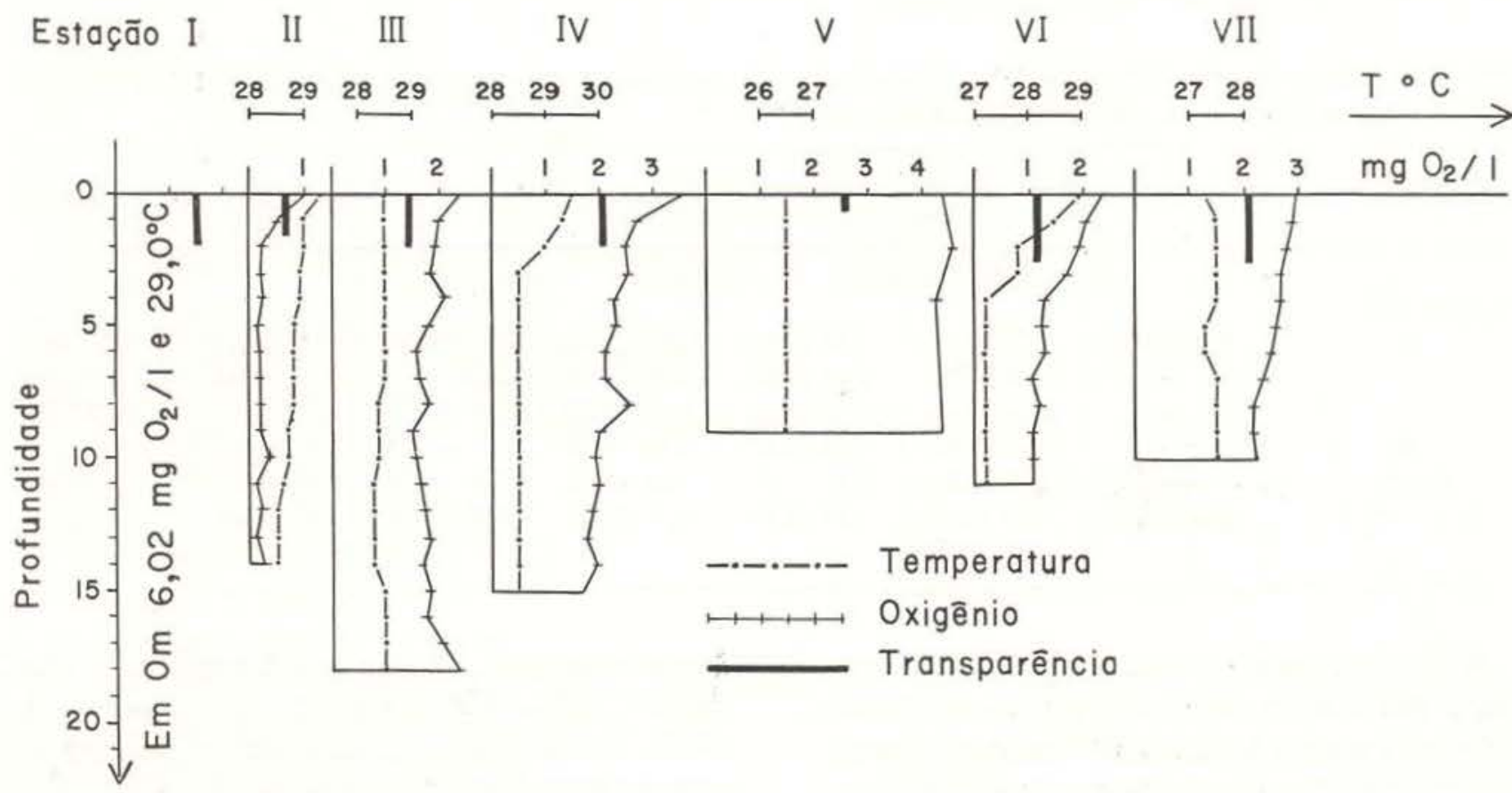

Fig. 4 - Valores de oxigènio, da temperatura e da transparência (profundidade de Secchi) nas diferentes estações da represa de Curuá-Una. (abril de 1978). 
TAB. 7 - Distribuiçăo e freqüência de macrófitas aquáticas na represa hidrelétrica de Curuá.Una.

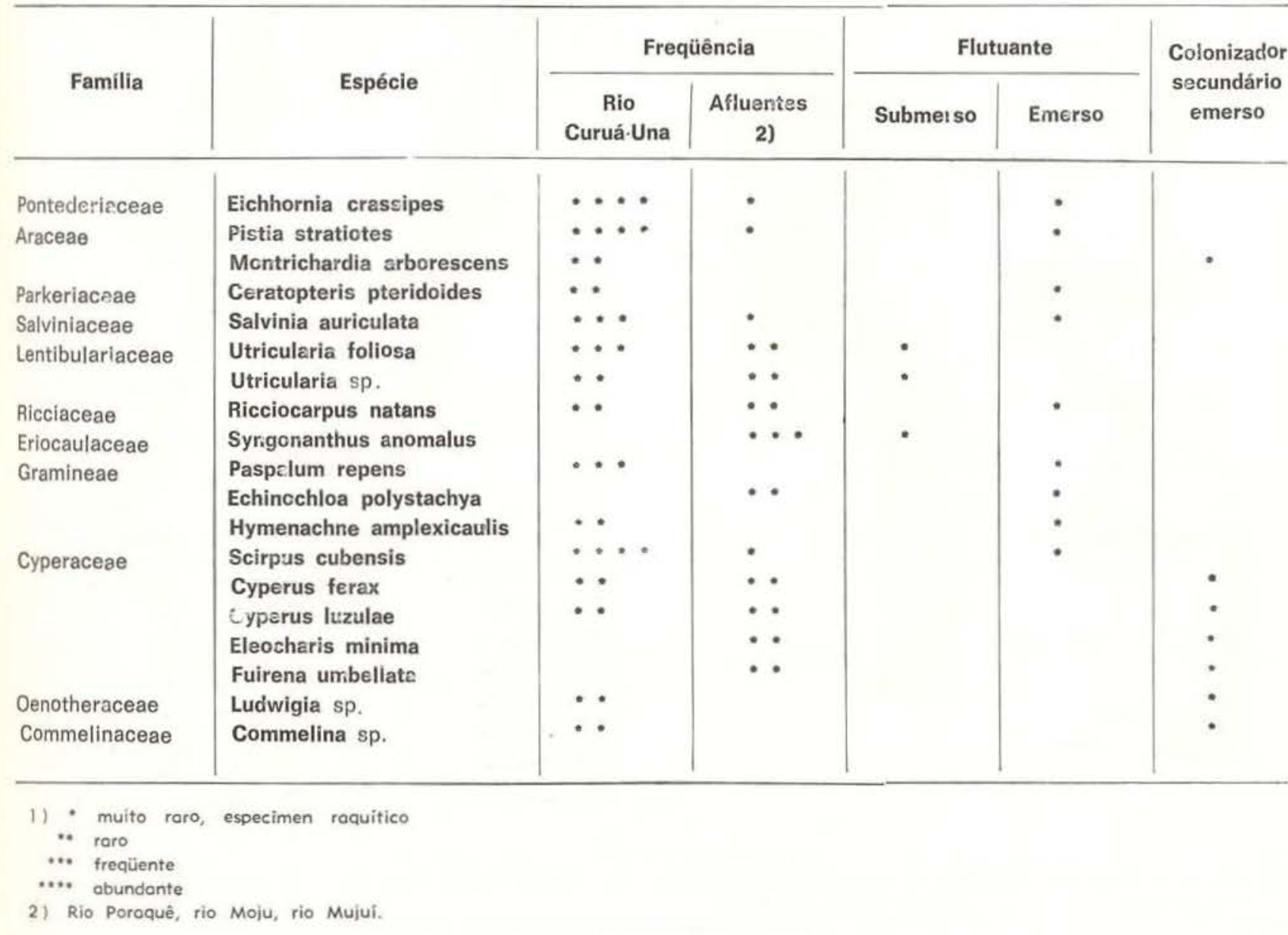

relação ao número das espécies quanto em relação à biomassa.

Considerando o fato de que as macrófitas aquáticas até agora não têm importância nas áreas influenciadas pelos afluentes, queremos focalizar somente as áreas influenciadas pelas águas do rio Curuá-Una. As figuras $5 a$, e $5 b$ mostram a distribuição e grau de cobertura de plantas flutuantes nesta área. As principais espécies são Eichhornia crassipes, Scirpus cubensis, Pistia stratiotes e Paspalum repens. Além disso, Salvinia auriculata foi freqüente mas 0 s espécimes eram muito pequenos e năo cobriam áreas grandes.

A distribuição das principais espécies na represa não foi uniforme. Eichhornia crassipes e Paspalum repens mostraram a maior freqüência perto da barragem, Scirpus cubensis na parte média, e Pistia stratiotes perto da entrada do rio Curuá-Una. Do km 71 para cima, não foram observadas macrófitas aquáticas. (Fig. 6).
Em geral, as plantas acompanham a antiga margem do rio, que é marcada por árvores mortas, deixando a área do leito livre, um fato que facilitou o levantamento cartográfico das comunidades. Mostrou-se claramente que a densiclade das comunidades aumenta em direção à barragem. Para quantificar essa tendência, à área total foi dividida em quatro trechos de $20 \mathrm{~km}$ de comprimento. Nestes, foram calculadas a área dos diferentes graus de cobertura 9 a área teórica, supondo $100 \%$ de cobertura. Os resultados encontram-se na Tabela 8. A densidade da vegetação representada pela soma das áreas com graus de cobertura VI e Vil aumenta de 5,6\% na área distante da barragem a $19.7 \%$ na área perto da barragem. De modo semelhante, aumenta a quantidade das plantas, expressa em percentagem da área total, supondo um grau de cobertura de $100 \%$. de $8,9 \%$ na área distante da barragem a $28,6 \%$ no trecho próximo à barragem. 

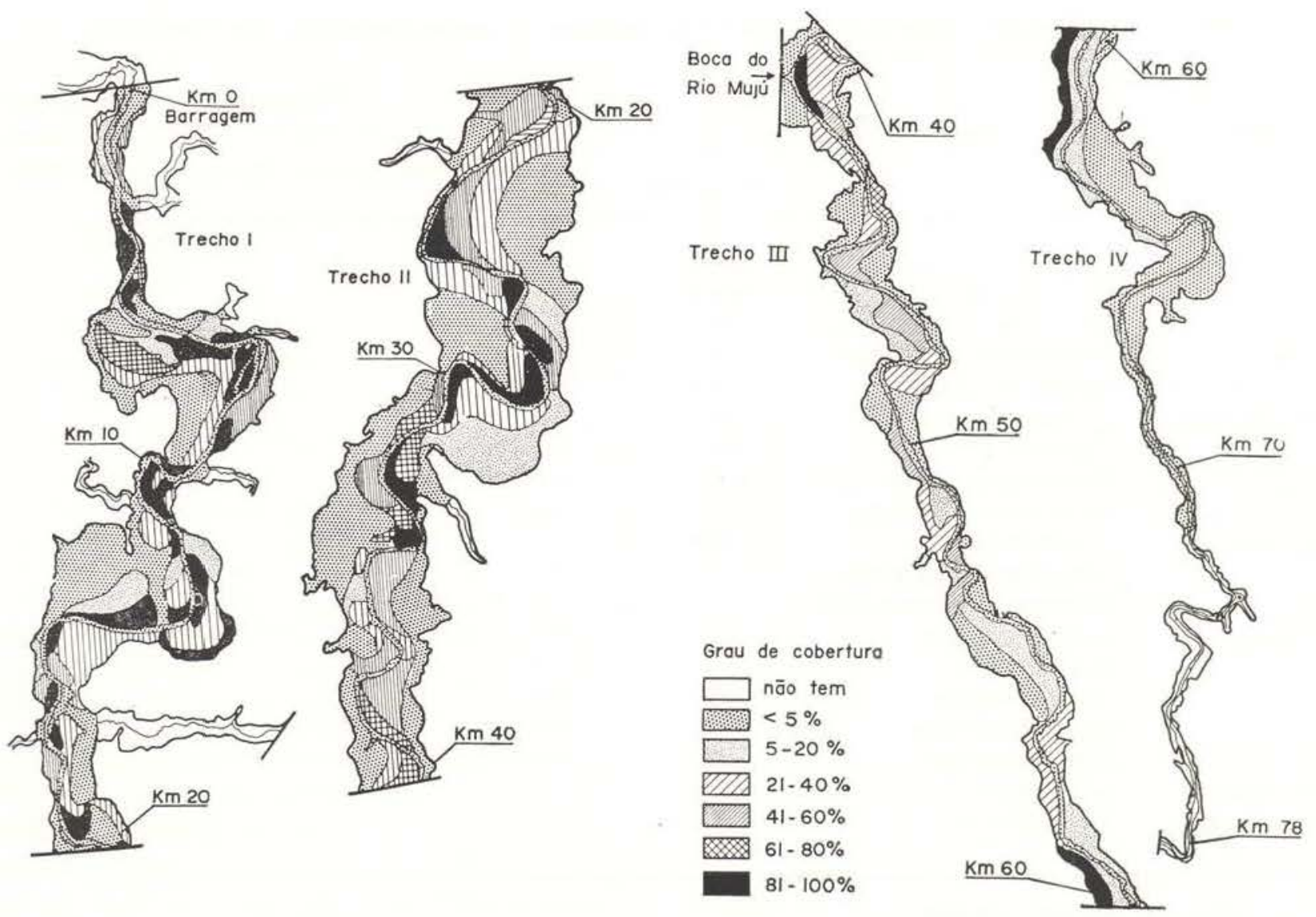

Fig. 5a, b - Grau de cobertura com macrófitas aquáticas nos trechos I e II (Fig. 5a) e III e IV (Fig. 5b) na área influenciada pelo rio Curuá-Una (maio de 1978).

\section{ZOOPLÂNCTON}

Trinta e quatro espécies de Cladóceres, representantes de 6 famílias e 20 gêneros, foram identificadas no material estudado. $\mathrm{Na}$ tabela 9, apresentam-se o número total e a abundância relativa (expressa em \%) das espécies nas diversas estações de coleta.

Observa-se que o número total de espécies varia sensivelmente entre 3 na estação $V$ e 24

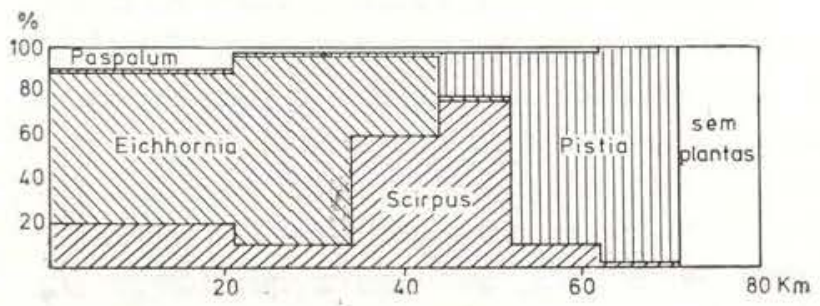

Fig. 6 - Participação percentual das espécies principais de macrófitas aquáticas ao longo do antigo leito do rio Curuá-Una (maio de 1978). na estação IV. Observa-se também que, com exceção das quatro espécies numericamente dominantes, Ceriodaphnia cornuta, Ceriodaphnia reticulata, Bosminopsis deitersi e Diaphanosoma sarsii, a maioria das espécies, principalmente das famílias Chydoridae e Macrothricidae, apresenta abundâncias relativas baixas $(<25,0 \%)$.

Compara-se a composição de Cladócera das diversas estações utilizando-se percentagem de semelhança, cuja fórmula é:

$$
P S=100-0.5 \quad \sum|a-b| .
$$

onde $a$ e $b$ são as abundâncias relativas de uma espécie em duas amostras. Esta fórmula, diferente de outras de similaridade, não assinala peso igual ao das espécies (Green, 1972). Os resultados desta análise, que se encontram na tabela 10, evidenciam bem a diferença entre as estações II e V, II e VII, e a semelhança entre as estações III e V, e III e VII, quanto às suas composiçöes. 
TAB. 8 - Densidade e extensã́o das macrófitas aquáticas nos diferentes trechos da área da represa hidrelétrica de Curuá-Una influenciados pelo rio Curuá-Una (maio de 1978).

\begin{tabular}{|c|c|c|c|c|c|c|c|c|c|c|c|c|c|c|c|c|c|c|}
\hline \multirow{3}{*}{$\begin{array}{c}\text { Trecho } \\
\mathrm{Km}\end{array}$} & \multirow{3}{*}{$\begin{array}{c}\left.\text { Area( }{ }^{(}\right) \\
\text {Total } \\
\mathrm{Km}^{2}\end{array}$} & \multicolumn{14}{|c|}{ ÁREA COM DIFERENTES GRAUS DE COBERTURA } & \multirow{2}{*}{\multicolumn{2}{|c|}{$\begin{array}{l}\text { Área total } \\
\text { com } 100 \% \\
\text { cobertura }\end{array}$}} & \multirow{3}{*}{$\frac{\text { Biomassa }}{\mathrm{t}}$} \\
\hline & & \multicolumn{2}{|c|}{ I } & \multicolumn{2}{|c|}{$\begin{array}{l}11 \\
5 \%\end{array}$} & \multicolumn{2}{|c|}{$\begin{array}{c}111 \\
5 \cdot 20 \%\end{array}$} & \multicolumn{2}{|c|}{$\begin{array}{c}\text { IV } \\
21.40 \%\end{array}$} & \multicolumn{2}{|c|}{$\begin{array}{c}V \\
41.60 \%\end{array}$} & \multicolumn{2}{|c|}{$\begin{array}{c}\text { VI } \\
61.80 \%\end{array}$} & \multicolumn{2}{|c|}{$\begin{array}{c}\text { VII } \\
81-100 \%\end{array}$} & & & \\
\hline & & $\mathrm{Km}^{2}$ & $\%$ & $\mathrm{Km}^{2}$ & $\%$ & $\mathrm{Km}^{2}$ & $\%$ & $\mathrm{Km}^{2}$ & $\%$ & $\mathrm{Km}^{2}$ & $\%$ & $\mathrm{Km}^{2}$ & $\%$ & $\mathrm{Km}^{2}$ & $\%$ & $\mathrm{Km}^{2}$ & $\%$ & \\
\hline $0-20$ & 17,19 & - & 一 & 7,47 & 43,5 & 1,67 & 9,7 & 3,59 & 20,9 & 1,09 & 6,3 & 0,61 & 3,7 & 2,76 & 15,0 & 4,93 & 28,6 & 4930 \\
\hline $20-40$ & 23,14 & 一 & - & 10,69 & 46,2 & 2,20 & 9,5 & 3,73 & 16,1 & 3,80 & 16,4 & 1,27 & 5.5 & 1,45 & 6,3 & 5,76 & 24,9 & 5760 \\
\hline $40-60$ & 10,80 & - & - & 4,61 & 42,7 & 2,11 & 19.5 & 2,32 & 21,5 & 1,17 & 10,8 & 0,20 & 1,9 & 0,39 & 3,6 & 2,16 & 20,0 & 2160 \\
\hline $60-78,5$ & 6.30 & 1,26 & 20,0 & 3,66 & 58,1 & 0,90 & 14,2 & 0,13 & 2.1 & - & - & - & - & 0,35 & 5,6 & 0,56 & 8,9 & 560 \\
\hline $\begin{array}{l}\text { Area } \\
\quad \text { total }\end{array}$ & 57,43 & 1,26 & 2,2 & 26,43 & 46,0 & 6,88 & 12,0 & 9.77 & 17,0 & 6,06 & 10,6 & 2,08 & 3,6 & 4,95 & 8,6 & 13,41 & 23.4 & 13410 \\
\hline
\end{tabular}

(•) - Todos os dados se referem à área indicado no mapa topográfico e na lsohipse de $67 \mathrm{~m}$. 
TAB. 9 - Abundância relativa (\%) das espécies de Cladócera encontradas na represa hidrelétrica de Curuá-Una em abril de 1978.

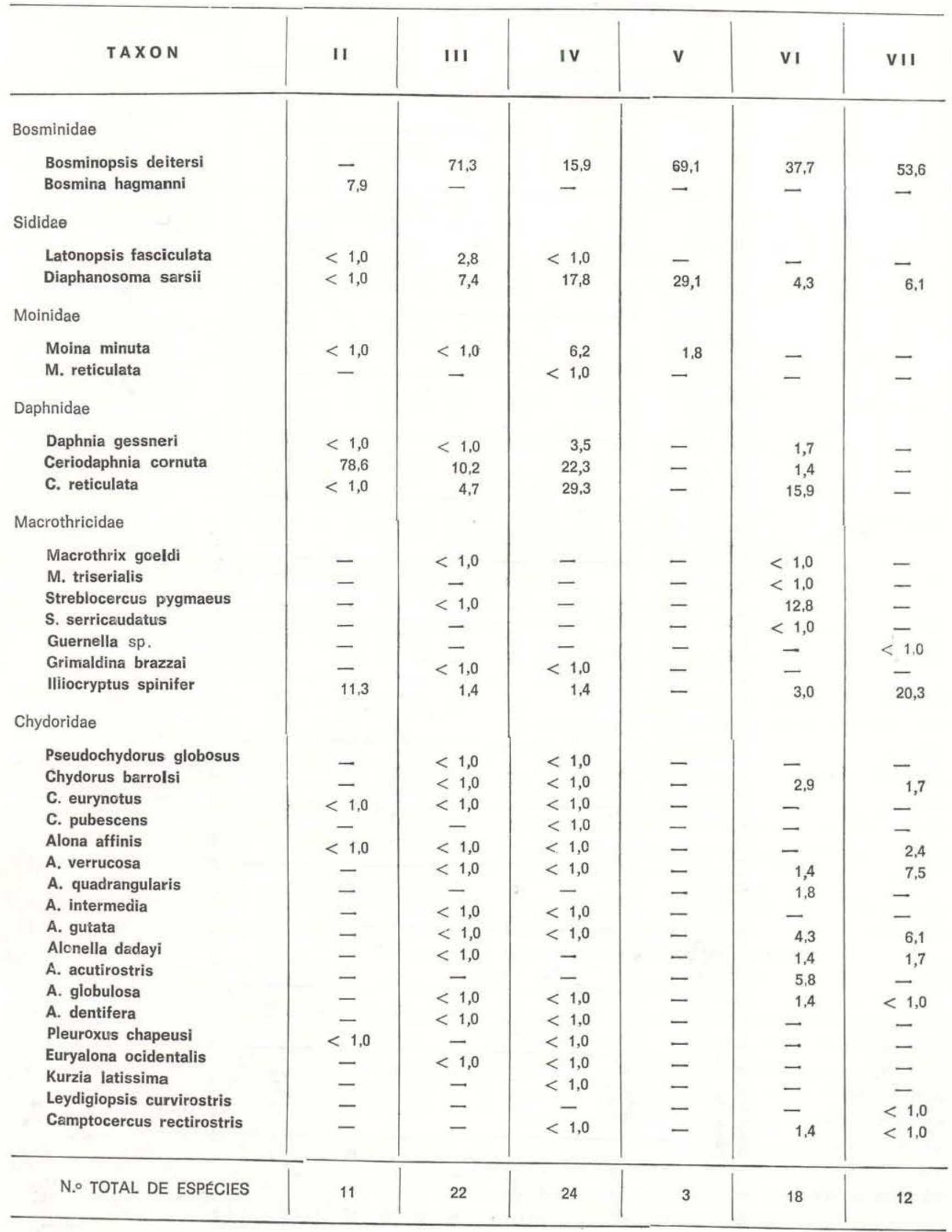




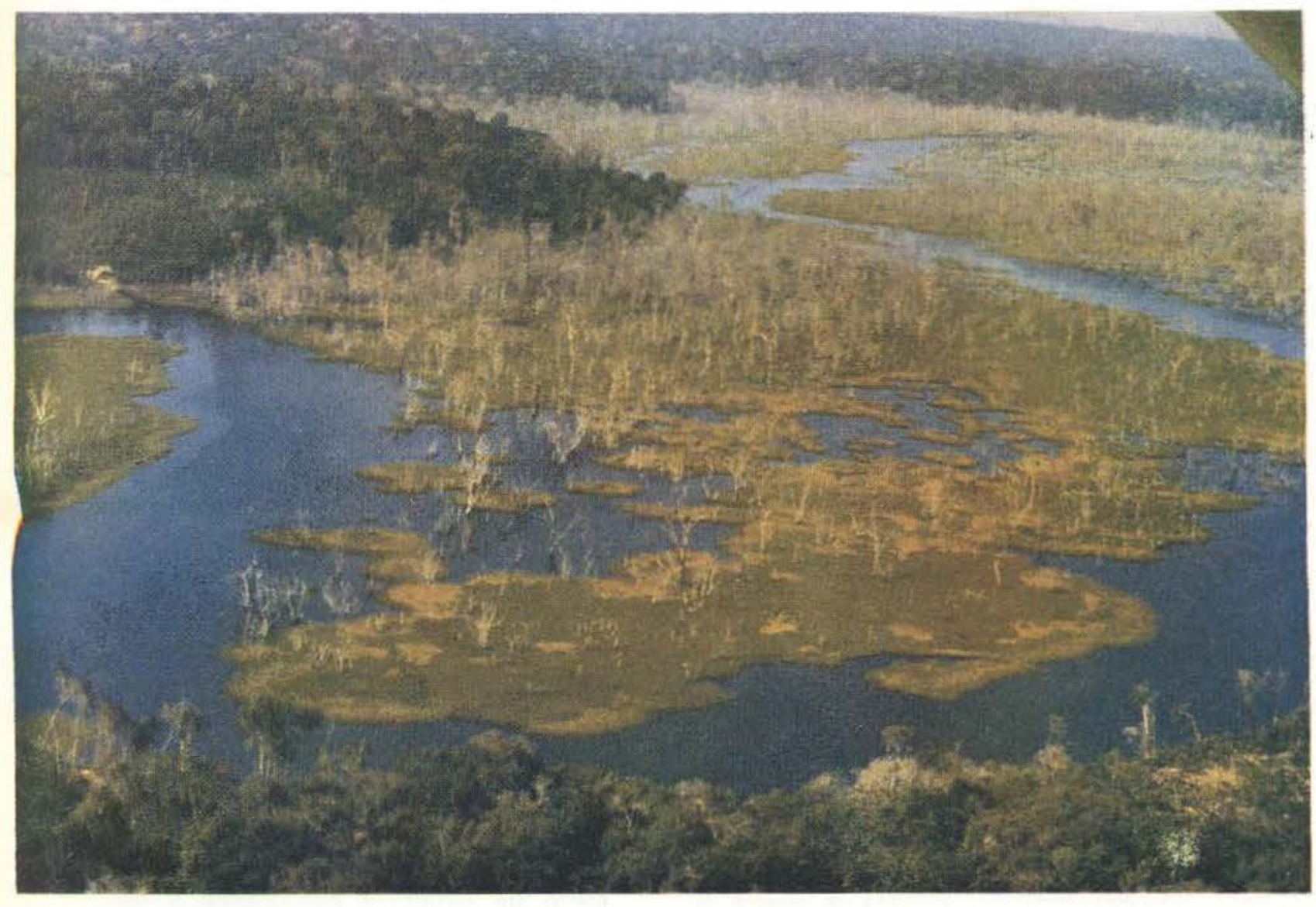

Fig. 7 - Vista aérea da represa de Curuá.Una, indicando o antigo leito do rio e grandes quantidades de árvores mortas como o desenvolvimento luxuriante de macrófitas aquáticas flutuantes. (maio de 1978).

TAB, 10 - Percentagem de semelhança de Cladócera da represa hidrelétrica de Curuá-Una em abril de 1978.

\begin{tabular}{r|rccccc}
\hline & & & & & & \\
Estaçōes & II & III & IV & V & VI & VII \\
& & & & & & \\
\hline II & X & 13,7 & 24,8 & 6,3 & 14,6 & 3,9 \\
III & 13,7 & X & 41,2 & 76,7 & 51,3 & 62,0 \\
IV & 24,8 & 41,2 & $X$ & 35,8 & 39,6 & 25,4 \\
V & 6,3 & 76,7 & 35,8 & $X$ & 42,9 & 59,8 \\
VI & 14,6 & 51,3 & 39,6 & 42,9 & $X$ & 56,8 \\
VII & 3,9 & 62,0 & 25,4 & 59,8 & 56,8 & $X$ \\
\hline
\end{tabular}

No que se refere às densidades absolutas, apresenta-se na Fig. $8 \sigma$ "standing-stock" $\left({ }^{4}\right)$ de Cladócera em cada estação de coleta. Por esta figura observa-se que os menores "standingstocks" nas estações V e VI, são cerca de 100 vezes menores do que o maior "standing-stock" encontrado na estação III. Também, com exceção da estação $\mathrm{V}$, as menores densidades de Cladócera se encontram nos afluentes do rio Curuá-Una, os rios Moju e Mujuí dos Campos.

O método de coleta empregado permite qu€ se apresente a distribuição vertical do "standing-stock" de Cladócera (Fig. 9), o qual mostra, com exceção da estação VI, uma tendência para os animais serem mais abundantes nos primeiros 5,0 metros da coluna d'água.

\section{ICTIOFAUNA}

A relação das espécies capturadas por estação consta na Tabela 11. Nas doze amostragens, em rio e igapó, foram capturadas um total de 1.069 peixes, distribuídos em 62 espécies agrupadas em 14 familias.

${ }^{(4}$ ) - "Standing-stock" - quantidade de organísmos (expressos em números de indivíduos, volume, peso seco, peso úmido) presentes por volume ou área, em dado instante (Matsumura-Tundisi, 1972).

Investigações... 




Fig. 8 - "Standing-stock" de Cladócera na represa de Curuá-Una em abril de 1978.

O total de capturas de espécies por estação não apresentou uniformidade proporcional ao tempo de amostragem, o mesmo ocorrendo ao número de espécimes capturados por estação (Tab 11).

A freqüência das espécies com maior captura consta na Tabela 12, estando representada sua percentagem em espécimes capturados e peso. No total, 10 espécies atingem $82 \%$ das capturas restando $18 \%$ para as 52 restantes.

Characidae foi a família mais abundante nas capturas por espécimes, seguida de Auchenipteridae, Serrasalmidae, Hemiodidae e Anostomidae, as demais com menor representatividade. O predomínio dos caracídeos acima da barragem cede sua supremacia aos auchenip terídeos abaixo da mesma.

As piranhas ou pirambebas apresentam um aumento nas capturas no interior da represa, estaçōes II e IV. Serrasalmus spp são duas vezes, ou mais, numerosas na represa, que nas demais estações acima ou abaixo da mesma.
Clupeidae só se capturou abaixo da barragem (est. I e VIII), enquanto Cichlidae não apresentou grande número de exemplares capturados, mesmo no interior da represa onde as condições lênticas parecem favorecer seu desempenho.

A nivel específico, Bryconops gracilis e Bryconops melanurus, apesar de sua abundância nas estações acima da barragem, não tiveram capturas registradas abaixo da mesma.

As trairas, Hoplias malabaricus e Hoplias sp, os pacus Myleus spp (A) e (C), o aracu Anostomus trimaculatus, as pirambebas Serrasalmus rhombeus e Serrasalmus serrulatus, o pirapucu ou urumará (nome local) Acestrorhynchus falcirostris, o mandi-peruano Auchenipterus nuchalis, os cangatis Parauchenipterus galeatus e Tatia sp, bem como os mandubés Ageneiostis brevifilis, estão distribuídos ao longo do rio com capturas registradas acima e abaixo da barragem.

Em espécies, ocorre maior número nas amostragens feitas nos igapós do que nos rios. Observou-se uma tendência à redução no número de espécies capturadas à medida que nos aproximamos da barragem, rio abaixo, tal fatę não sendo registrado nas estações I e VIII, quando esta última apresentou menor número que aquela mais próxima à represa .

Em espécies amostrados, as estaçōes IV. $V$ e VIII apresentam supremacia no rio, e em igapó, nas estações I e II, a primeira com pequena vantagem

Em termos de peso, Acestrorhynchus falcirostris é a espécıe mais destacada, tendo seus maiores indices registrados nas estaçōes II e IV da represa. (Tab. 13). Serrasalmus rhombeus é a segundã espécie em peso, com exem. plares de maior porte sendo capturado acima da represa, na estação $\mathrm{V}$, alguns com peso superior a 2 quilos. Myleus spp também apresen. tam exemplares de bom porte.

Comparando-se o peso do pescado coletado em rio e ıgapó verifica-se que houve predomínio em peso para amostragem em rio, nas estações V e VIII, e para igapó nas estações I, II e IV. Espécies como Myleus sp (A). Serrasalmus rhombeus, Acestrorhynchus falcirostris, Bryconops melanurus, Charax paucira- 

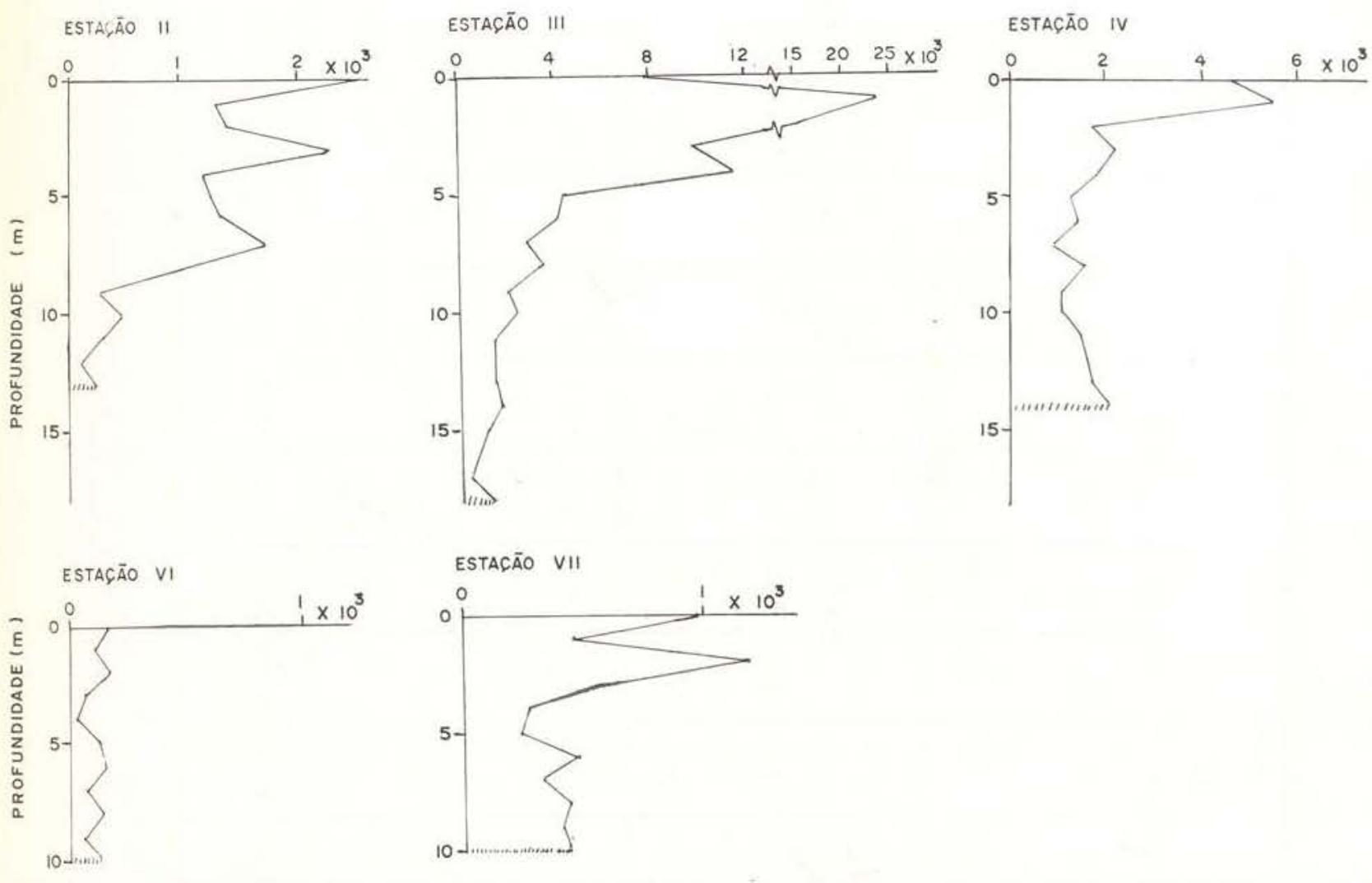

Fig. 9 - Distribuição vertical de Cladócera $\left(n \circ \cap\right.$ ind $/ \mathrm{m}^{3}$ ) na represa de Curuá-Una em abril de 1978.

diatus e Auchenipterichthys sp, em geral apresentaram maiores capturas, em peso, no igapó; por sua vez, Myleus sp (B), Bryconops gracilis, Auchenipterus nuchalis e Centromochlus heckelli estão melhor representados nas capturas de rio, assim como Acestrorhynchus microlepis.

\section{DISCUSSĀo}

\section{SITUAÇÃO HIDROQUÍMICA}

Baseando-se nos caracteres físico-químicos Sioli (1967) classifica as águas naturais da regiăo amazônica em 3 tipos: água branca, água preta e água clara.

Através dessa classificação, as águas dos rios Curuá-Una, Moju e Mujuí dos Campos são difíceis de classificar. Aparentemente pertencem, quimicamente, ao grupo das águas claras e águas pretas, respectivamente, porém, a turbidez relativamente grande do rio Curuá-Una (transparência $0.6 \mathrm{~m}$ ), e a condutividade elétrica elevada ( $27 \mathrm{uS} . \mathrm{cm}^{-1} / 20^{\circ} \mathrm{C}$ na estação V) poderiam indicar uma afinidade à água branca. A coloração escura dos afluentes Moju e Mu- juí dos Campos indica sua classificação como água preta, porém sua alta transparência de $2,6 \mathrm{~m}$, indica uma tendência maior ao grupo de áqua clara.

Nos últimos anos, estudos pormenorizados de Furch (1976), para a classificação das águas amazônicas, aumentaram o número dos parâ. metros úteis, analisando, não apenas as concentrações totais, mas também as concentrações relativas dos elementos. As águas brancas podem ser consideradas como águas carbonatadas com alta percentagem de $\mathrm{Ca}$ e $\mathrm{Mg}$, pertencendo ao tipo mais comum do mundo. As águas claras e pretas, porém, devem ser considera. das como águas "não carbonatadas", com alta percentagem de $\mathrm{Na}$ e $\mathrm{K}$. Esta hipótese foi verificada por Junk \& Furch (1980), estudando 46 igarapés e rios no trecho da estrada Cuiabá-Porto Velho-Manaus. Calculando os valores percentuais dos valores médios do $\mathrm{Ca}, \mathrm{Mg}, \mathrm{Na}$ e $\mathrm{K}$ nas diferentes estações da represa, e comparanclo-se esses valores com os valores indicados por Junk \& Furch (1980), mostra-se que nenhum dos três tributários da represa tem 
TAB. 12 - Freqüência relativa (\%) dos exemplares capturados (EC) e de seu peso (P) nas diferentes estações, referente ao mês de abril de 1978 . Os dados se referem às espécies com maior número de capturas totais.

\begin{tabular}{|c|c|c|c|c|c|c|c|c|c|c|c|c|c|c|c|c|}
\hline & \multicolumn{2}{|c|}{ Est. I } & \multicolumn{2}{|c|}{ Est. II } & \multicolumn{2}{|c|}{ Est. IV } & \multicolumn{2}{|c|}{ Est. V } & \multicolumn{2}{|c|}{ Est. VI } & \multicolumn{2}{|c|}{ Est. VII } & \multicolumn{2}{|c|}{ Est. VIII } & \multicolumn{2}{|c|}{ Total } \\
\hline & EC & $\mathbf{p}$ & EC & $\mathbf{P}$ & EC & $\mathbf{P}$ & EC & $\mathbf{P}$ & EC & $\mathbf{P}$ & EC & $\mathbf{p}$ & EC & $\mathbf{P}$ & EC & $p$ \\
\hline Hemiodopsis sp & - & - & - & - & - & 一 & 6,88 & 4,79 & 1,12 & 2.13 & - & - & - & - & 1,87 & 1,35 \\
\hline Myleus sp $(A)^{*}$ & 8,65 & - & 2,07 & $一$ & 一 & 一 & 0,72 & 2,15 & 1,12 & 6,91 & 0,99 & 2.07 & - & - & 1,22 & 4,03 \\
\hline Myleus sp (B) & - & - & - & - & - & - & 1,45 & 20,46 & - & 一 & - & - & - & - & 0,37 & 5,10 \\
\hline Myleus sp. (C) & 0,96 & 1,42 & - & - & - & - & 2,54 & 15,49 & - & - & 1,98 & 7,04 & - & - & 0,94 & 4,60 \\
\hline Serrasalmus rhombeus & 2,88 & 3,02 & 8,11 & 8,54 & 7,26 & 11,17 & 4,35 & 15,44 & 2,25 & 19,15 & 4,95 & 3,12 & - & - & 5,14 & 9,43 \\
\hline Acestrorhynchus falcirostris & 0,96 & 1,07 & 15,14 & 44,57 & 10,08 & 34,10 & 0,72 & 0,70 & 4,49 & 22,88 & 2,97 & 14,56 & - & - & 5,89 & 16,66 \\
\hline A. microlepis & - & - & 37,84 & 15,17 & 17,34 & 7,17 & 0,72 & 0,41 & 10,11 & 4,71 & 15,84 & 8,75 & - & - & 13,10 & 4,84 \\
\hline Bryconops gracilis & - & - & 0,54 & 0,11 & 17,74 & 5,03 & 51,09 & 12,24 & 62,92 & 22,25 & 44,56 & 16,81 & - & - & 26,85 & 6,93 \\
\hline B. melanurus & - & - & 23,78 & 6,19 & 12,10 & 3,13 & 13,04 & 2,83 & $7,8^{-}$ & 1,89 & 0,99 & 0,29 & - & - & 11,04 & 2,43 \\
\hline Charax pauciradiatus & - & - & - & - & 14,11 & 2,96 & - & - & 1,12 & 0,19 & 6,93 & 1,66 & - & - & 4,02 & 0,73 \\
\hline Auchenipterichthys $\mathrm{sp}$ & 27,88 & 10,57 & - & - & - & - & - & - & - & - & - & - & 10,60 & 3,05 & 3,37 & 1,86 \\
\hline Auchenipterus nuchalis & 5,77 & 2,73 & - & - & 15,73 & 15,53 & 8,33 & 5,55 & - & - & 10,89 & 13,76 & - & - & 7,39 & 5,90 \\
\hline Centromochlus heckelii & 13,46 & 2,11 & - & - & - & - & - & - & - & - & - & - & 39,39 & 6,13 & 3,74 & 0,96 \\
\hline Sub-total & 60,56 & 40,53 & 85,41 & 74,58 & 94,36 & 79,09 & 89,84 & 80,06 & 91,00 & 80,11 & 90,10 & 68,05 & 49,99 & 9,18 & 84,90 & 64,92 \\
\hline Outras capturas & 39,42 & 59,47 & 14,59 & 25,41 & 5,65 & 20,92 & 10,14 & 19,95 & 8,99 & 19,90 & 9,90 & 31,94 & 50,00 & 90,82 & 15.06 & 35,17 \\
\hline
\end{tabular}

(•) - Espécies incluidas por sua representatividade em peso. 
TAB. 13 - Peso $(g)$ das espécies de peixes das diferentes estaçōes, com maior registro de capturas no mês de abril de 1978, desdobradas em rio (R) e igapó (I).

\begin{tabular}{|c|c|c|c|c|c|c|c|c|c|c|c|c|c|c|c|}
\hline \multirow{2}{*}{ Espécie } & \multicolumn{2}{|c|}{ Estação 1} & \multicolumn{2}{|c|}{ Estação II } & \multicolumn{2}{|c|}{ Estaçăo IV } & \multicolumn{2}{|c|}{ Estação V } & \multirow{2}{*}{$\begin{array}{c}\begin{array}{c}\text { Estação } \\
\text { VI }\end{array} \\
\text { R }\end{array}$} & \multirow{2}{*}{$\begin{array}{c}\begin{array}{c}\text { Estação } \\
\text { VII }\end{array} \\
\mathbf{R}\end{array}$} & \multicolumn{2}{|c|}{ Estação VIII } & \multicolumn{3}{|c|}{ Totais p/espécie } \\
\hline & $\mathbf{R}$ & I & $\mathbf{R}$ & I & $\mathbf{R}$ & 1 & $\mathbf{R}$ & I & & & $\mathbf{R}$ & 1 & $\mathbf{R}$ & 1 & $\mathbf{T}$ \\
\hline Hemiodopsis $s p$ & - & $\overrightarrow{-}$ & - & - & - & - & 577 & 579 & 148 & - & - & - & 725 & 579 & 1156 \\
\hline Myieus sp (A)* & - & 2755 & 一 & - & - & 一 & - & 520 & 479 & 150 & - & -1 & 629 & 3275 & 3904 \\
\hline Myieus sp $(B)^{*}$ & - & - & - & - & - & - & 4940 & - & 一 & 一 & - & - & 4940 & - & 4940 \\
\hline Myleus sp $(C)^{*}$ & - & 200 & - & - & - & 一 & 3370 & 370 & 一 & 510 & 一 & - & 3880 & 570 & 4450 \\
\hline Serrasalmus rhombeus & 20 & 405 & 59 & 1204 & 720 & 1435 & 316 & 3411 & 1328 & 226 & 一 & - & 2669 & 6455 & 9124 \\
\hline Acestrorhynchus falcirostris & - & 150 & 1703 & 4886 & 2060 & 4516 & 68 & 100 & 1587 & 1055 & - & - & 6473 & 9656 & 16125 \\
\hline Acestrorhynchus microlepis & - & $\cdots$ & 634 & 1024 & 1170 & 212 & 100 & - & 327 & 634 & - & - & 3450 & 1236 & 4686 \\
\hline Bryconops gracilis & - & - & - & 16 & 504 & 466 & 2555 & 400 & 1543 & 1218 & - & - & 5820 & 882 & 6702 \\
\hline B. melanurus & - & - & 129 & 786 & 344 & 259 & 143 & 541 & 131 & 20 & - & - & 767 & 1586 & 2353 \\
\hline C. pauciradiatus & - & -- & 一 & - & 62 & 508 & - & 一 & 13 & 120 & - & - & 195 & 508 & 703 \\
\hline Auchenipterichthys sp & 585 & 900 & - & - & - & - & - & $\rightarrow$ & - & - & 13 & 302 & 598 & 1202 & 1800 \\
\hline Auchenipterus nuchalis & 384 & - & - & - & 1539 & 1455 & 1339 & 一 & - & 997 & - & - & 4259 & 1455 & 5714 \\
\hline Centromochlus heckeliii & 296 & - & - & -1 & - & 一 & - & - & - & 一 & 633 & - & 929 & 一 & 929 \\
\hline Sub-total & 1285 & 4410 & 3110 & 7916 & 6399 & 8851 & 13408 & 5921 & 5556 & 4930 & 646 & 302 & 35334 & 27400 & 62734 \\
\hline Outras & 2025 & 6330 & 924 & 2833 & 1267 & 2768 & 1641 & 3175 & 1380 & 2314 & 4799 & 4584 & 14350 & 19690 & 34040 \\
\hline Total por estaçäo & 3310 & 10740 & 4034 & 10743 & 7666 & 11619 & 15049 & 9096 & 6936 & 7244 & 5445 & 4886 & 49684 & 47090 & 96774 \\
\hline
\end{tabular}

(•) - Espécies incluidas nesta Tobela por sua representatividade em peso. 
afinidade à água branca (Tab, 14). A quantidacie de metais alcalinos é bem maior do que a quantidade dos metais alcalino-terrosos, sendo esta relação especialmente acentuada nos rios Mujuí (25:1) e Moju (22:1) enquanto que o rio Curuá-Una na estação $\mathrm{V}$ tem uma relação de 2:1. A turbidez do rio Curuá-Una no $\mathrm{Km} 80$ aparentemente é ligada somente à erosão provocada pela época chuvosa, sem ligação com as característices químicas da água branca. Visitas às cabeceiras do rio Curuá-Una e rio Mujui dos Campos provaram que ambos os rios têm alta transparência e pouca coloração escura.

Temos que considerar, assim, que, a coloração escura, especialmente nos rios Moju e Mujuí é provocada pela grande quantidade de matéria orgânica em decomposição, na própria represa. O grupo de águas claras, levando em conta os caracteres de Sioli (1967), é um grupo muito heterogêneo, que também foi mostrado por Junk \& Furch (1980), e que se mostra também no presente trabalho. O rio CuruáUna difere do ponto de vista químico, claramente dos seus afluentes Moju e Mujuí, sendo ele $2-2,5$ vezes mais rico em sais minerais totais, tendo também um $\mathrm{pH}$ claramente mais alto $(5,4$ e $4,1-4,3$ respectivamente). As quantidacies totais de $\mathrm{Ca}$ são 60 até provavelmente 100 vezes maiores que as dos rios Moju e Mujui, e os valores de $\mathrm{Mg}, 10$ a 20 vezes maiores no rio Curuá-Una, que nos seus afluentes. Estas diferenças explicam-se pelas diferenças geoquímicas nas respectivas áreas de captação. Como já foi mencionado o rio CuruâUna, além de sedimentos terciários, nas suas

TAB, 14 - Concentraçöes relativas de $\mathrm{Na}, \mathrm{K}, \mathrm{Ca}$ e $\mathrm{Mg}$ (mg \%, valores médios nas diferentes esta. çōes da represa hidrelétrica de Curuá Una e o valor médio mundial (VMM), conforme Bowen, (1966).

\begin{tabular}{rrrrrrrrr}
\hline & I & II & III & IV & V & VI & VII & VMM \\
\hline $\mathrm{Na}$ & - & 50,5 & 49,6 & 45,7 & 38,1 & 82,6 & 70,4 & 22,7 \\
$\mathrm{~K}$ & - & 27,7 & 27,3 & 28,4 & 30,7 & 13,9 & 25,3 & 8,3 \\
$\mathrm{Ca}$ & - & 10,0 & 10,6 & 12,3 & 15,4 & 0,9 & 0,6 & 54,2 \\
$\mathrm{Mg}$ & - & 11,9 & 12,6 & 13,6 & 15,8 & 2,6 & 3,7 & 14,8 \\
\hline
\end{tabular}

cabeceiras, atravessa faixas carboníferas rela. tivamente ricas em sais minerais, especialmente em $\mathrm{Ca}$ e $\mathrm{Mg}$, enquanto que, na área de captação dos rios Moju e Mujuí, dominam exclusivamente áreas de sedimentos terciários, ácidos, e extremamente pobres em sais minerais.

$\mathrm{Na}$ represa a correnteza do rio Curuá-Una é reduzida drasticamente, provocando a sedimentaçãe das partículas em suspensão, como mostra o aumento na transparência de $60 \mathrm{~cm}$ na estação $\mathrm{V}$ para $2 \mathrm{~m}$ na estação IV. Porém, mostrou-se uma homogeneidade relativamente alta em todos os parâmetros medidos na coluna vertical. O curto tempo de retenção da água na represa, calculada para o mês de abril (épocá chuvosa) em 29,1 dias, provocou um fluxo contínuo da água, que foi calculada em $112 \mathrm{~m}$ por hora, baseando-se no comprimento do leito antigo do rio Curuá-Una, de $78 \mathrm{~km}$, e $80 \mathrm{~m}$ por hora baseando-se no comprimento total da represa de $56 \mathrm{~km}$. Um valor médio, de cerca de $100 \mathrm{~m} /$ hora, deveria representar, em geral, a velocidade do fluxo da água no eixo horizontal da represa neste período. Isso aparentemente provocou turbulências que impediram o desenvolvimento de uma pronunciada estratificação vertical térmica e química. Achamos, por isso, plenamente justificado basear nossa discussão dos dados hidroquímicos, nos valores médios das respectivas estações. Por outro lado, mostra-se uma estratificação horizontal bem nítida, ao longo do eixo longitudinal da represa. Ao longo do rio CuruáUna, dentro da própria represa, quase todos os parâmetros medidos mostram um declive na sua concentração, do afluente para o efluente, sendo somente os valores da estação IV um pouco mais elevado de que os da estação V. Este leve aumento pode ser atribuído a efeitos de lixivação da área inundada e da vegetação morta. Este efeito de lixiviação está sendo aparentemente superado pelos efeitos de diluição pelos afluentes mais ácidos e pobres em sais minerais, como é aparente nas estações III, II e I.

O oxigênio diminui gradativamente de 4,4 $\mathrm{mg} / \mathrm{I}$ (55,6\% de saturação) na entrada da represa, para $0,26 \mathrm{mg} / \mathrm{l}$ (3,4\% de saturação) perto da barragem, mostrando somente um 
leve aumento na camada superficial em algumas estações (Fig. 4). Calculando-se a quantidade total de oxigênio que penetra na represa com base no valor médio mensal da afluência diária de $17.130 .000 \mathrm{~m}^{3}$, e da concentração de $\mathrm{O}_{2}$ de $4,4 \mathrm{mg} / \mathrm{l}$, chega-se a uma quantidade de $75.400 \mathrm{~kg}$ de oxigênio por dia. Ao mesmo tempo, a represa perde, diariamente, a quantidade de $4.500 \mathrm{~kg}$ de oxigênio pela efluência $(0,26 \mathrm{mg} / \mathrm{l})$. Porém, temos que levar em conta, além do oxigênio que entra pelos afluentes na represa, também a quantidade de oxigênio produzido pelas plantas aquáticas, principalmente pelo fitoplâncton no próprio re. servatório. Infelizmente, não temos dados de Curuá-Una à disposição. Porém, para ter-se uma idéia geral sobre a proporção da produçâo parece ser justificado usar dados de Schmidt (1976), medidos no rio Negro, perto de Manaus, considerando o fato de que a transparência e as concentrações dos nutrientes mostram-se relativamente pouco diferentes das condições na represa.

De acordo com Schmidt (1976), o valor médio anual da produção líquida do fitoplâncton no rio Negro é de $0,063 \mathrm{~g} \mathrm{C} / \mathrm{m}^{2} / \mathrm{dia}$. Isto corresponde a uma produçăo de $0,168 \mathrm{~g}$ $\mathrm{O}_{2} / \mathrm{m}^{2} /$ dia

Considerando uma superfície, não coberta de macrófitas flutuantes, de $83 \mathrm{~km}^{2}$, são produzidos no reservatório cerca de $14.000 \mathrm{~kg}$ de $\mathrm{O}_{2} /$ dia.

Outra fonte de oxigênio é o perifiton. De acordo com medidas de Rai (com. pess.), a prcdução de perifiton variou entre $0,1 \mathrm{~g}$ e 3,1 $\mathrm{g} \mathrm{C} / \mathrm{m}^{2} /$ dia em placas colocadas na camada eufótica de um lago de água clara perto de Manaus. Considerando um valor médio de $3,20 \mathrm{~m}$ de camada eufótica e uma densidade de 100 árvores mortas de $50 \mathrm{~cm}$ de diâmetro/ha, a área à disposição de perifiton, na represa, corresponde a $500 \mathrm{~m}^{2} / \mathrm{ha}$. Supondo uma produçâo de $1 \mathrm{~g} \mathrm{C} / \mathrm{m}^{2} / \mathrm{dia}$, isso corresponde a uma quantidade total de $11,000 \mathrm{~kg}$ de oxigênio/ dia para os $83 \mathrm{~km}^{2}$ da represa não cobertos com inacrófitas flutuantes.

As informações sobre as concentrações de oxigênio na vegetação flutuante (Junk, 1973) indicam que ela não contribui em maior esca- la para a oxigenaçẩo da água. Os órgãos assimilatórios das piantas ficam, na sua maioria, acima da superfície da água. Além disso, as densas massas de vegetação inibem a circulação da água e com isto a passagem de oxigênio. proveniente do perifiton associado, e do ar da superfície, para as camadas inferiores. Porém, existe a possibilidade de que o leve fluxo de água na represa permita uma circulação entre as plantas.

O fator mais difícil de ser avaliado é a difusão de oxigênio do ar para a água. Estudos recentes (Broecker \& Peng, 1974, Emerson, 1975) mostram que, apesar de certas restrições, a difusão de oxigênio pode ser calculada através da fórmula

$$
\mathrm{F}=(\mathrm{Ca}-\text { Csat }) \mathrm{D} / \mathrm{Z}
$$

onde, $\mathrm{F}=\mathrm{mg} \mathrm{O}_{2} \mathrm{~m}^{-2} \mathrm{dia}^{-1}$

$D=$ coeficiente de difusão de oxigênio. (Conforme Deacon, (1977) $=$ cerca $2,5 \cdot 10^{-5} \mathrm{~cm}^{2} \cdot \mathrm{sec}^{-1}$ considerando $27^{\circ} \mathrm{C}$ )

$\mathrm{Ca}=$ concentração de oxigênio, em mg. $\mathrm{m}^{-3}$, na superfície da água.

Csat $=$ concentração da saturação de oxigênio, em $\mathrm{mg} \cdot \mathrm{m}^{-3}$, na água.

$Z$ = espessura da camada superficial.

Emerson (1975) indica uma espessura média da camada superficial da água de $600 \mu$ para peqquenos lagos protegidos da ação do vento Supondo um valor médio de temperatura da água de $27^{\circ} \mathrm{C}$, e de $2 \mathrm{mg} \mathrm{O}_{2} / \mathrm{I}$ na água perto da superfície da represa, chegamos ao seguinte cálculo:

$$
\begin{gathered}
\mathrm{D} / \mathrm{Z}=\frac{0,000025}{0,06} \cdot \frac{\mathrm{cm}^{2}}{\mathrm{sec} \cdot \mathrm{cm}}=0,000417 \\
\mathrm{~cm} / \mathrm{sec}=0,36 \mathrm{~m} / \mathrm{dia} \\
\mathrm{Ca}-\mathrm{Csat}=(2.000-7.860) \mathrm{mg} \cdot \mathrm{m}^{-3} \\
=-5.860 \mathrm{mg} \cdot \mathrm{m}^{-3} \\
\mathrm{~F}=-5.860 \cdot 0,36 \frac{\mathrm{mg} \cdot \mathrm{m}}{\mathrm{m}^{3} \cdot \mathrm{dia}}=2.110 \\
=-2.110 \mathrm{mg} \cdot \mathrm{m}^{-7} \cdot \mathrm{dia}^{-1}-2.110 \mathrm{~kg} \cdot \mathrm{Km}^{-2} \mathrm{dia}^{-1}
\end{gathered}
$$


Considerando uma área de água sem ma. crófitas na represa de $83 \mathrm{~km}^{2}$ chegamos a uma quantidade total de $174.900 \mathrm{~kg} \mathrm{O} /$ dia entran do na represa pela difusão.

De acordo com estes cálculos, estăo entrando diariamente na represa as seguintes quantidades de oxigênio :

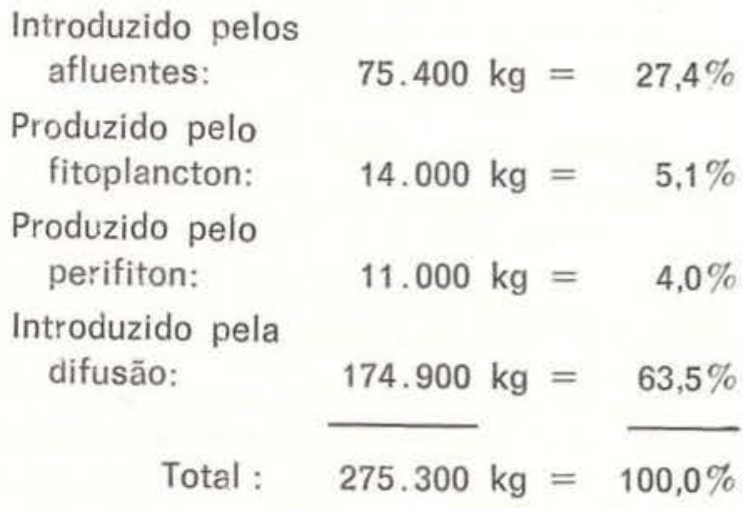

Perda pela efluência: $\quad 4.500 \mathrm{~kg}$

\section{Consumo Total: $\quad 270.800 \mathrm{~kg}$}

Isto corresponde a um consumo de $2.8 \mathrm{~g}$ de $\mathrm{O}_{2} / \mathrm{dia} / \mathrm{m}^{2}$ e cerca de $0,5 \mathrm{~g}$ de $\mathrm{O}_{2} \mathrm{~m}^{-3} / \mathrm{dia}$.

Supomos qua o consumo de oxigênio seja bem maior nos primeiros anos por causa da maior quantidade de material orgânico em geral e especificamente de material de fácil decomposição (folhas, plantas herbáceas) que são introduzidos ao sistema logo após a inundação. O consumo deverá baixar no futuro, gradativamente, com a diminuição do material orgânico à disposição na represa.

Estamos plenamente cientes do fato de que estes cálculos são bastante generalizados. simplificados e hipotéticos. Porém, achamos muito importante haver pelo menos uma idéia sobre a ordem de magnitude da participação das várias fontes que contribuem com oxigênio para a represa, e sobre a quantidade de oxigênio consumido na mesma.

Os cálculos mostram que a quantidade principal de oxigênio está sendo contribuída pela difusão. Quanto mais fina a camada superficial, tanto maior a taxa de difusão. A espessura da camada superficial depende do movimento da água provocado pelo vento e a correnteza, tendo, per isto os fatores climáti$\cos , 3$ morfologia da bacia hidrográfica, e o tempo de retenção da água na represa, uma alta importância para o abastecimento do reservatório com oxigênio. A formação de uma estratificação térmica pronunciada não permite a passagem do oxigênio, entrando pela superfície e produzido pelo fitoplancton e o parifiton, ao hipolimnion. Neste caso, o hipolimnion depende exclusivamente do oxigênio introduzido pelos afluentes, que contribuem somente com $27,4 \%$ para o balanço total. Esta quantidade de oxigênio pode ser consumida totalmente em pouco tempo, provocando anoxia e formação de gás sulfídrico.

Acreditamos que a continuação da coleta destes dados possibilitará, no futuro, previsões gerais em relação ao balanço de oxigênio em outras represas amazônicas.

\section{MACROFITAS AQUATTICAS}

Entre as espécies de macrófitas aquáticas encontradas na represa de Curuá-Una podemos citar Eichornia crassipes, Pistia stratiotes, Salvinia auriculata e Ceratopteris pteridoides, como altamente problemáticas em represas tropicais. Estas espécies são muito comuns nas várzeas do Solimões/Amazonas, porém, em condições naturais, não se desenvolvem em quantidadies tão exuberantes, como está ocorrendo em outras regiōes tropicais e, no caso de Eichhornia crassipes e Pistia stratiotes, na própria represa de Curuá-Una. Vários fatores provavelmente controlam o crescimento destas plantas na Amazônia, tais como: grandes flutuações periódicas do nível de água; doenças e parasitas endêmicos; baixas concentrações de nutrientes; baixo $\mathrm{pH}$ nas águas; e concorrência com outras espécies aquáticas. A importanncia de cada um desses fatores é, até agora difícil de avaliar, porque, em condições naturais, sempre ocorreram vários (ou todos) em conjunto. Os lagos da região amazônica encontram-se, na sua grande maioria, nas áreas de inundação dos grandes rios. Eles são submetidos às grandes oscilaçōes periódicas do nível dos rios, que são combinadas com grandes mudanças da área inundada. A represa Curuá-Una sendo o primeiro "lago" sem mudanças grandes do nível, mostra que Eichhornia crassipes, Pistia stratiotes e Scirpus cubensis tem o potencial de se desenvolver em 
grandes quantidades, superando, pelo menos. nos primeiros anos, o efeito controlador de doenças e parasitas existentes na região. Porém, principalmente Eichhornia crassipes, mostrou efeitos consideráveis de parasitas (Cornops longicorne e Neochetina bruchei), os quais deveram ter reduzido o crescimento das plantas, porém, sem conseguir controlá-las. Scirpus cubensis nada apresentou, e Pistia stratiotes, somente pouco efeito de parasitas no período estudado.

A ocorrência esporádica das plantas nas áreas influenciadas pelos afluentes do rio Curuá-Una mostrou que, baixas concentrações de sais minerais em combinação com pH baixo, limitam o crescimento da maioria das plantas flutuantes. Os poucos espécimens encontrados eram geralmente muito pequenos e raquíticos, porém não podemos dizer qual seja o fator limitante para as plantas, o $\mathrm{pH}$ baixo ou as concentracōes baixas de nutrientes. Estudos de Berg (1961) no rio Congo indicam que valores de $\mathrm{pH}$ abaixo de 4,2 , em combinação com concentrações baixas de sais minerais são tóxicos para Eichhornia crassipes. Esta observação está conforme a de que, em condições naturais na região amazônica, Eichhornia, Pistia, Salvinia, Ceratopteris e Paspalum não ocorrem em agua com baixo $\mathrm{pH}$ e baixa condutividade elétrica. Somente Scirpus cubensis foi encontrado ocasionalmente em tais condições, mas em pequenas quantidades. Característico para este tipo de águas são outras espécies como por exemplo, representantes da família Eriocaulaceae, Syngonanthus anomalus (que já é freqüente na área da represa influenciada pelos rios Moju e Mujuí), e Tonina fluviatilis, que ainda não foi encontrada.

A distribuição heterogênea das plantas na área influenciada pela água do rio CuruáUna, tanto em relação à sua quantidade total quanto em relação à sua composição florística, pode ser interpretado pelo tempo de inundação. O nível de água subiu gradativamente (Fig. 3), permitindo primeiramente a colonização da área perto da barragem. Esta área mostra também o maior grau de cobertura, enquanto a área perto da influência do rio Curuá-Una ainda não foi ocupada pela vegetação. Aparen- temente, Pistia tem as melhores condições de ocupar esta área vazia, sendo mais perto da barragem superada pelas espécies de maior porte. Tudo indica que a comunidade de macrófitas aquáticas ainda não chegou ao equilíbrio, tanto em relação à quantidade total quanto no que concerne à composição florística.

Supondo uma quantidade média de $10 \mathrm{t}$ de matéria seca/ha. as macrófitas aquáticas representam uma biomassa de $13.410 \mathrm{t}$. A aplicação de herbicidas para o controle dessa ve-getação teria como conseqüência um aumento drástico no consumo de oxigênio por processos de decomposição com efeitos provavelmente desastrosos para a fauna aquática, especialmente os peixes. É aconselhável tentar usar métodos naturais, tais como mudanças do nível de água e introdução de herbívoros aquáticos, para controlar o crescimento da vegetação.

\section{ZOOPLÂNCTON}

Entre diferentes localidades de um corpo d'água, organismos zooplanctônicos comumente apresentam grandes variações em sua densidade e composição (Rzóska, 1966; Burgis, 1969; Green, 1972; Gliwicz \& Rybak, 1976), e este fenômeno é evidente na represa de CuruáUna.

$\mathrm{Na}$ estação V do rio Curuá-Una observou-se o menor número de espécies (3), e também a menor densidade de animais $\left(1.100 / \mathrm{m}^{3}\right)$. Estes resultados não são surpreendentes visto que o efeito do represamento é pequeno, e a correnteza relativamente veloz, nesta região do reservatório.

Nas outras estações do rio Curuá-Unâ, II, III e IV, há um aumento significativo tanto na densidade dos animais quanto no número de espécies. Enquanto inúmeros fatores influenciam o desenvolvimento de cladóceros, correnteza, neste caso, possivelmente pode ser destacade visto que diminui suficientemente, dentro do reservatório, para que as populações possam aumentar "em sítio", mesmo nesta época de vazão alta. 
$\mathrm{O}$ aumento no número de espécies nas es tações II, III e IV, se deve ao aparecimento de representantes das famílias Daphnidae, Macrothriciciae e Chydoridae. É interessante notar que, de modo geral, espécies das duas últimas famílias são mais comumente encontra. das essociadas ao bentos, a macrófitas aquáticas, perifiton, e aflorações de algas. No entanto, em decorrência do deslocamento de macrófitas, ou da ação de chuvas, enchentes, oncias e vento, estas são carregadas de seus ambientes preferenciais para as regiões pelágicas. Nas estações II, III e IV, as espécies das famílias Chydoridae e Macrothricidae apresentam abundâncias relativas muito baixas $(<1,0 \%)$, e podem ser consideradas ocasionais. Provavelmento, estas são provenientes das macrófitas aquáticas que delimitam o leito original do rio.

A presença de diversas espécies das familias Chydoridae e Macrothricidae nas estações iocalizadas nos afluentes do rio Curuá-Una (VI e VII) é particularmente interessante em virtude de o desenvolvimento de macrófitas nesta região do reservatório ser bastante escasso. Sugere-se portanto, que estas espécies provavelmente são provenientes das aflorações de algas observadas entre os troncos e galhos das árvores inundadas, pois Gliwics \& Rybak (1976), por exemplo, mostram que concentrações de algas propiciam ambientes favoráveis ao desenvolvimento de espécies "pseudoplanctônicas".

$O$ ínaice de percentagem de semelhança permite que se compare a composição de Cladócera entre diversas estações mesmo quando a densidade de animais varia sensivelmente.

Os maiores índices de semelhança encontrados entre as estações III e V, e III e VII, refletem a dominância $(>50,0 \%)$ de Bosminopsis deitersi nas mesmas (Tab. 10). Por outro lado, os menores índices, encontrados entre as estações II e V, \& II e VII, refletem não somente a dominância de Bosminopsis deitersi nas estações $V$ a VII como também a ausência de Ceriodaphnia cornuta nestas e a dominância desta última espécie na estação II onde Bosminopsis deitersi está ausente.
Ambas, Bosminopsis deitersi e Ceriodaphnia cornuta apresentam ampla distribuição em lagos da Amazônia (Brandorff, 1977; Hardy, 1978) e nos trópıcos de modo geral, por serem cosmotropicais (Brandorff, 1978; Green, 1972), o que implica, a uma larga faixa de tolerância, diferentes fatores ambientais. As razões para Bosminopsis deitersi estar ausente na estação II e Ceriodaphnia cornuta estar ausente na estação VII permaneceram obscuros.

Diferente das variáveis químicas e temperatura, e com exceção da estação VI, os cladóceros não apresentam uma distribuição vertical uniforme, tendem a ser mais abundantes nos primeiros 5,0 metros dá coluna d'água. Esta distribuição possivelmente é um reflexo da distribuição de ítens alimentares tais como algas e bactérias, as quais, de acordo com Schmidt (1969), no seu estudo no lago do Castanho, também apresentam máximos de abundância nas camadas superficiais da coluna d'água. Contudo isso, resta ser averiguado.

$\mathrm{Na}$ estação $\mathrm{VI}$ a distribuição vertical dos Cladóceros é relativamente homogênea, e não mostra tendências para os animais se concentrarem em determinada profundidade. Neste caso, é interessante levar em consideração os estudos de Brook \& Rzóska (1954) no reservatório Gebel Aulyia no Nilo Branco. Estes autores observaram que em regiōes do reservatório menos influenciadas pelo represamento do rio, o zooplâncton apresentou uma composição mista, de formas típicas do limnoplâncton e formas adventícias, uma densidade baixa, e perfis verticais com pouca ou nenhuma estratificação. Na estação VI, mesmo que a correnteza seja menos pronunciada do que na estação V, as abundâncias relativas, altas, das formas "menos típicas do limnoplancton", o baixo "standing-stock" (semelhante a estação V), c a ausência de estratificação dos animais no perfil vertical, possivelmente apontam a uma região do reservatório onde, pelo menos, nesta época de vazão alta, condições fluviais. de uma forma ou de outra, ainda prevaleçam.

$\mathrm{Na}$ estação VII, semelhante, quimicamente, à estação VI, hesita-se em sugerir que as condições físicas também sejam semelhantes às da estação $\mathrm{VI}$ em virtude da leve estratificação dos animais na coluna d'água. 
$\mathrm{Na}$ realidade, a baixa densidade de animais, nesta estação, em comparação com as estaçôes do rio Curuá-Una, merece mais atenção e estudos futuros.

\section{ICTIOFAUNA}

A necessidade de levantamentos prévios da ictiofauna de rios que serão utilizados para a construção de represas, antes do início das obras, visando à utilização desses dados na análise dos efeitos do bloqueamento, bem como a previsão e correção de acontecimentos indesejáveis, tem sido destacada por vários autores, que lamentam sua falta ou utilizam essas análises prévias em seus trabalhos (Sidthimunka, 1968; Bardach \& Dussart, 1973; Lelek \& El Zarka, 1973; Bowmaker, 1975; Pantulu, 1975; Fernando, 1977 b). No rio Curuá-Una, não houve levantamentos anteriores à construção da represa, o que dificulta ou impossibilita as análises das comunidades de peixes préexistentes. Além disso, nossos estudos somente levaram em consideração espécies de maior porte, por causa dos equipamentos usados. Mesmo assim, mostraram-se várias ten. dências sintetizando em resposta à composiçăo dos estoques em nível de espécies.

Niissen (in: Leentvaar, 1971), trabalhando em condiçōes semelhantes, no lago Brokopondo, salientou a redução do número de espécies deste comparado à região superior do rio Suriname e de outros. Sidthimunka (1968) citanos a redução do número de espécies do Ubolratana reservoir na Tailândia, de 74 espécies coletadas antes do bloqueamento do rio para 43, após a construção da barragem completar um ano. Tais fatos corroboram com os resultados das amostragens, já que o menor número de espécies capturadas ocorreu nas estaçōes localizadas no interior da represa, II e IV, a primeira destas com 14 espécies e a segunda com 16, enquanto que acima da represa e abaixo da mesma, as capturas foram de 24 espécies em ambas as estações, I e V.

0 número de espécimes capturados, por outro lado, foi maior nas estações da represa que nas demais, com exceção da estação $V$. não se comparando as estações VI e VII por motivos óbvios. A distribuição da freqüência dos predadores (percentagem) por espécimes capturados e peso, nas diferentes estações (Tab. 12), apresenta um nítido aumento desses no interior da represa, Ests. II e IV, em comparação com as amostragens feitas a montante (Est. V) e a jusante da barragem (Ests. I e VIII). Entretanto, esse aumento de predadores, que tem sido verificado em outros lagos formados pelo represamento de rios. como nos iagos Kainji, Cimljansk, Kujbyshev, Kariba, Volta e outros (Lelek \& El-Zarka, 1973) mostra-se pouco nítido na represa de CurláUna, se compararmos as amostragens feitas nas mesmas com as das estações de dois da seus tributários, os rios Moju (est. VI) e o Mujui (est. VII) .

Uma vez que essas estações foram situadas em regiões com sinais de alagamento permanente, porém em água corrente, admitiu-se que os efeitos do represamento em termos de mudança na ictiofauna ali também ocorram, reconhecendo-se, contudo, a necessidade de maiores estudos a respeito, uma vez que somente foi amostrada nas estações VI e VII a ictiofauna de rio.

A similaridade faunística (Tab. 15) analisada pelo coeficiente de Sorensen (1948) aproxima as amostragens das estações II, IV, e VII, com indices superiores a $50 \%$. A estação V. comparada às acima citadas, apresenta-se me-

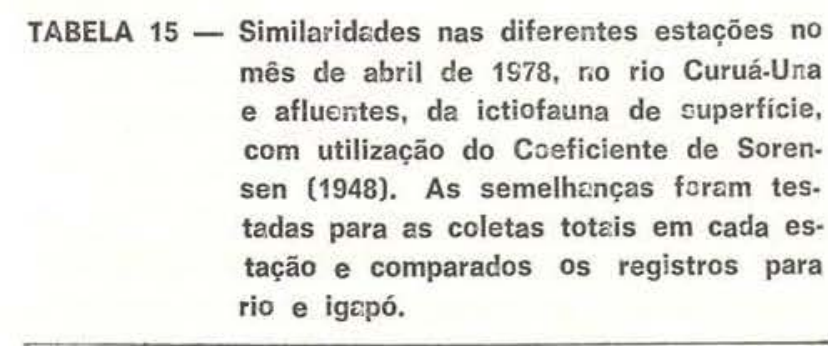

\begin{tabular}{cccccccc}
\hline Estaçōes & I & II & IV & V & VI & VII & VIII \\
\hline I & (34) & 26 & 15 & 33 & 25 & 34 & 36 \\
II & & $(67)$ & 53 & 47 & 60 & 58 & 11 \\
IV & & & $(67)$ & 35 & 50 & 61 & 16 \\
IV & & & & $(63)$ & 40 & 54 & 13 \\
VI & & & & &.. & 57 & 11 \\
VII & & & & & &.. & 5 \\
VIII & & & & & & & $(9)$ \\
\hline
\end{tabular}

Os coeficientes entre parênteses referem-se à similaridade entre rio e igapó de uma mesma estoçăo. 
nos próxima, com índices variando entre 35\% (est. IV) e $54 \%$ (est. VII). Menor relacionamento com a fauna acima da barragem apresentam as estações I e VIII. A primeira destas tem seu mais elevado registro com a estação VII $(34 \%)$ enquanto que a estação VIII o tem com IV $(16 \%)$. Entre si estas apresentam $36 \%$ de similaridade.

É evidente que uma análise faunística nesse molde deve servir apenas como orientação para estudos ulteriores, visto que, na própria estação VIII, a similaridade da fauna de rio, comparado ao igapó, foi de apenas $9 \%$, muito baixa, portanto, não sendo superior a $67 \% \mathrm{em}$ nenhuma das outras estações amostradas em rio e igapó. Novas amostragens nesses locais certamente definirão melhor a composição comunitária.

Admitiu-se, primariamente, estar a composição faunística da região dividida em duas comunidades: a primeira compreendendo as estações acima da barragem; a segunda, as situadas abaixo mas com pouca associação entre os rios Curuá-Una (est. I) e o rio Curuá do Sul (est. VIII). Até que ponto essa divisão foi influenciada pela construção da barragem não é possível verificar, pela falta de estudos anteriores.

O grande número de predadores nas estações no interior da represa, a nosso ver, quer por sua presença nas malhadeiras, quer por sua ação ativa, é um fator que deve ser levado em consideração na análise faunística, uma vez que devemos admitir a ocorrência de vício nas amostragens provocado pelo natural afastamento de peixes de presa, inclusive de espécies menos freqüentes, alterando a composição da ictiofauna. A despesca em intervalos menores talvez reduza a possibilidade de uma alteração na composição da comunidade, em espécies. Baseando-se nos dados limnológicos descritos nos capitulos anteriores, podem constar-se os seguintes pontos :

- O número de espécies dos peixes originais do rio, no interior da represa, está aparentemente, se reduzindo, seguindo o padrão descrito em comunidades ictiológicas de outros lagos artificiais estudados em re- giões tropicais. As condições lênticas no novo ambiente levaram à redução do número de onívoras, que predominam nas amostragens lóticas. Bryconops gracilis e os Hemiodideos tiveram maiores capturas nas águas oxigenadas dos rios demonstrando sua preferência por este ambiente. Bryconops melanurus parece tolerar melhor a redução no oxigênio dissolvido nas águas da repiesa, sendo mais capturado no igapó, talvez ocupando diferente nicho que Bryconops gracilis;

- A proporção dos predadores capturados é mais elevada no interior da represa, fato também observado e descrito em outros lagos artificiais. Acestrorhynchus falcirostris e Acestrorhynchus microlepis parecem melhor adaptados ao novo ambiente apresentando capturas mais elevadas;

- A preferência por áreas sombreadas, pelos peixes, citada por Petr (1975), deve ser levada em consideração no controle do desmatamento das encostas marginais, que se verifica na represa de Curuá-Una, uma vez que parece ocorrer um "preferendum" dessas áreas pelos peixes, haja vista 0 maior número de capturas no igapó da estação II;

- Em espécimes, e em peso, as águas correntes apresəntam, em geral, volume maior que as amostragens em igapó. O inverso, porém, ocorre em termos de espécies que são mais numerosas nesse último biótopo. O peso médio por exemplar capturado é sempre maior no igapó, demonstrando a ocorrência de exemplares em estágio avan. çado de desenvolvimento nas áreas protegidas por vegetação;

- Nenhuma observação pode ser feita sobre a variação dos níveis d'água uma vez que apenas uma das turbinas se encontrava em funcionamento, sendo insuficiente para drenar quantidades elevadas a ponto de alterar notadamente o nível da represa.

PESCA

Dc ponto de vista da pesca, pode verificarse que peixes de pequeno porte não são comu. mente utilizados na alimentação pela população 
da região, apesar de sua abundância. Tal fato pode ser atribuído à preferência pela caça que o povo local demonstra, e que ali existe em abundância, ou à existência de espécies nobres, de maior parte e excelente paladar como os pacus e pirapucus, que são mais eficientemente capturados com os aparelhos de pesca de que dispōem. A maior riqueza em espécimes capturados por nós, acima da barragem, foi verificada para Bryconops gracilis, Aces trorhynchus microlepis e Bryconops melanurus. Nossas malhas de $15 \mathrm{~mm}$ capturaram $89 \%$ de Bryconops gracilis, $79 \%$ de Acestrorhynchus microlepis e $92 \%$ de Bryconops melanurus, cabendo o restante das capturas à malhas de $20 \mathrm{~mm}$. Os habitantes locais utilizam malhadeiras com malhas acima de $30 \mathrm{~mm}$ de distância entre nós.

Hemiodopsis $\mathrm{sp}$, as oranas ou charutos (nome local), são peixes de delicado paladar e abundantes acima da represa, porém seu consumo pela população não foi registrado. Sua captura maior foi feita por nós, com malhas de $30 \mathrm{~mm}$. ou menos, o que talvez justifique sua ausência no cardápio local. Infelizmente parec€m não se adaptar às condições da represa, o que se verifica pela ausência de captura dessa espécie nas estações II e IV, o que limi. ta sua provável utilização em piscicultura.

Acestrorhynchus falcirostris e Myleus spp são procurados pelos locais na região acima da barragem por causa de seu bom porte e da boa qualidade de sua carne. Leporinus agassizi é especie que atinge tamanho elevado e tem carne de boa qualidade, sendo de esperar-se suł utilização na alimentação, fato que não acontece localmente. É provável que tal decorra de suas capturas pequenas, que năo permite uma utilização em maior escala. Serrasalmus rhombeus não tem a preferência alimentar da população, apesar da ocorrência de exemplares de grande porte. O temor dos acidentes provocadns por sua agressividade e fortes mandíbulas afasta o desejo de capturá-lo.

\section{AgradeCIMENTOS}

O projeto foi iniciado pelas Centrais Elétricas Brasileiras S/A. (ELETROBRÁS) e o Conselho Nacional de Desenvolvimento Cisn- tífico e Tecnológico (CNPq) que, através do Instituto Nacional de Pesquisas da Amazônia (INPA), em Manaus, realizou o mesmo. As Centrais Elétricas do Pará (CELPA), responsáveis pela represa, colaboraram com a hospedagem e assistência no campo. Agradecemos a estes órgãos e também ao Eng ${ }^{\circ}$ Wilton $\mathrm{H}$. Bentes Diretor da Represa de Curuá-Una, e aos seus colaboradores, por sua participação e ajuda nos trabalhos de campo. Finalmente gostariamos de agradecer ao nosso assistente José Carlos Paula Raposo e ao pessoal de Apoio do Departamento Peixe/Pesca pela ajuda ao nosso trabalho.

\section{SUMMARY}

Curuá-Una Reservoir is the first hydrelectric dam of the Amazon basin and is being studied by the Instituto Nacional de Pesquisas da Amazônia (INPA), Manaus, in agreement with the Centrais Elétricas Rrasileiras S/A (ELETROBRAS) and the Centrais Elétricas do Pará (CELPA). Analyses of hydrochemical, aquatic macrophyte, zooplankton (Cladocera), and fish material colected April and May, 1978, in the reservoir show the following ecological situation. The Curuá-Una River and its tributaries belong, from a chemical point of view, to the complex "clear water" group, however the Curuá-Una's tributaries above the dam site, are very acid and extremly poor in mineral salts, while the Curuá-Una River itself presents a higher $\mathrm{pH}$ and a greater concentration of salts. The dilution effect of the tributaries in the Curuá-Una River probably surmounts the local enriching effects of soil and vege. tation drainage.

No pronounced temperature or chemical stratification were observed probibly bocause of the low retention time of the water in the reservoir, 29.1 days. which resulted in a theoretical current velocity of aproximatiy $100 \mathrm{~m} /$ hour. The reduction in oxygen between afluent and efluent is distinct but $\mathrm{H}_{2} \mathrm{~S}$ was not observed during this sampling period.

Great quantities of floating aquatic macrophytes occur in the reservoir and the principal species are Eichhornia crassipes, Scirpus cubensis, Pistia stratiotes and Paspalum repens. The abundance and distribution of the plants show clear relationships with the chemical situation of the reservoir as well as with the history of the inundation period.

34 species of Cladocera belonging to 6 families were identified, however, the density of animals was very low. The distribution and standing-stock of Cladocera show differences between the collecting sites as well as a vertical stratification. 3 species, Bosminopsis deitersi, Ceriodaphnia cornuta and Ceriodaphnia reticulata, represented $53 \%-99 \%$ of the total number of specimens. 
62 species of fish, belonging to 14 fam:lies were collected. Some species showed preference for the reservoir area while others were found predominantly above or below. The frequency of the "piranhas" was two times greater in the reservoir while members of the Auchenipteridae were more frequent outside the reservoir. Clupeidac were found only below the dam site. The total quantitly of fish was relatively low as many specimens were small.

\section{REFERENCIAS BIBLIOGRÁFICAS}

BAGNOULS, F. \& GAUSSEN, H.

1963 - Os climas biológicos e sua classificaçăo.

B. Geogr., Rio de Janeiro, 22:545-566.

BARDACH \& DUSSART

1973 - Effects of man-made lakes on ecosystems. In: Man-made Lakes Their problems and environmental effects. Washington, D.C.. Amer. Geophysical Union. p. 811-817.

BERG, A.

1961 - Rôle ecclogique de la cuvette congolaise sur la croisance de la jacinthe d'eau (Eichhornia crassipes) (Mart. Solms). Academie Royale des Sciences d'Outre-Mer 12(3): 1-120.

BOWMAKER, A.

1975 - Fisheries productivity of Lake Kariba, Tobacco Forum of Rhodesia, 2:17-25.

BRANDORFF, G.O.

1977 - Untersuchungen zur Populationsdynamik des Crustaceenplanktons Lago Castanho (Amazonas, Brasilien). Tese de Doutoramento, Universidade Kiel. 108 p.

BRASIL. Departamento Nacional de Meteorologia

1972 - Balanço hídrico do Brasil. Rio de Janeiro. $94 \mathrm{p}$.

BRASIL, Departamento Nacional de Produção Mineral.

1975 - Projeto RADAM - Folha SB. 21 - Tapajós. Rio de Janeiro. $488 \mathrm{p}$.

1976 - Folha SA. 21 . Santarém. Rio de Janeiro. $522 \mathrm{p}$.

BRAUN, $R$

1952 - Limnologische Untersuchungen an einigen Seen im Amazonasgebiet. - Schweitz. $\mathbf{z}$. Hydrol. $14(1): 1-128 \mathrm{p}$.

BROECKER, W.S. \& PENG, T.-H

1974 - Gas exchange rates between air and sea. Tellus, 26(12):21-35.

BROOK, A.J. \& RZOSKA, J.

1954 - The influence of the Gebel Aulyia Dam on the development of Nile plankton. J. Animal Ecology, 23:101-114.

BURGIS, M.J.

1969 - A preliminary study of the ecology of zooplankton in Lake George, Uganda. Verh. Internat. Verein. Limnol., 17:297-302.
DEACON, E.L.

1977 - Gas transfer to and across an air-water interface. Tellus, 29(4):363-374.

DONSELAAR, J.V.

1968 - Water and marsh plants in the artificial Brokopondo Lake (Surinam, S. America) during the first three years of its existence. Acta Bot. Beerl., 17(3):1833-196.

ELSTER, H.J.

1958 - Zum Problem der quantitativen Methoden in der Zooplanktonforschung. Verh. Internat. Verein Limnol., 13:961-973.

EMERSON, S.

1975 - Gas exchenge rates in small Canadian shiel lakes. Limnology and Oceanography, 20(5):754-761.

FERNANDO, C.H.

1977 a - Investigations on the aquatic fauna of tropical ricefields with special reference to South East Asia. GEO-ECO-TROP. 1: 169-188.

$1977 \mathrm{~b}$ - Fisheries of natural lakes and man-made reservoirs - Symposium on the development and utilization on inland fishery resources. In: Indo-Pacific Fisheries Council Proceedings 17th session. 1.G. Dunn (ed.) Bangkok, Thailand, p. 9-12.

FURCH, K.

1976 - Haupt - und Spurenmetallgehalte zentralamazonischer Gewässertypen. Biogeographica, 7:27-43.

GLIWICZ, Z.M. \& RYBAK, J.I.

1976 - Zooplankton. In: Piecznska, E. (ed.) Selected probiems of lake littoral ecology. Warszawa, Wydawhichthwa Uniwersyteto. p. 69-96

GOLTERMAN, H.L.; CLYMO, R.S. \& OHNSTAD, M.A.M. 1978 - Methods for physical and chemical analysis of fresh waters. Oxford, London, Ediburgh, IBP Handbook 8, Blackwell Scientific Publications. 213 p.

GREEN, J.

1972 - Freshwater ecology in Mato Grosso, Central Brazil. II. Associations of the Cladocera in meander lakes of the Rio Suia Missu. J. Nat. Hist., 6:215-227.

HARDY, E.R.

1978 - Composiçăo do zooplâncton em cinco lagos da Amazônia Ceritral. Săo Carlos. 143 p. Tese de Mestrado.

HARTT, C.F.

1874 - Report of a reconnaissance of the lower Tapajós. B. Cornell Univ., Ithaca, 1(1/2): 11-37.

IRMLER, U.

1975 - Ecological studies of the aquatic soil invertebrates in three inundation forests of Central Amazonia. Amazoniana, 5(3):337-409 
1976 - Zusammensetzung, Besiedlungsdichte und Biomasse der makrofauna des Bodens in der emersen und submersen Phase zentralamazonischer Oberschwemmungswälder. Biogeographica, 7:79-99.

JUNK, W.J.

1970 - Investigations on the ecology and production-biology of the "floating meadows" (Paspalo-Echinochloetum) on the Middle Amazon. I. The floating vegetation and its ecology. Amazoniana, 2(4):449-495.

1973 - Investigations on the ecology and production-biology on the "floating meadows" (Prspalo-Echinochloetum) on the Middle Amazon. II. The aquatic fauna in the root zone of floating vegetation. Amazoniana, $4(1): 9-102$

1975 - Aquatic wildlife and fisheries. - The use of ecological guidelines for development in the American humid tropics. Caracas 1974. Papers and Proceedings, :109-125.

JUNK, W.J. \& FURCH, K.

1980 - Química da água e macrófitas aquáticas de rios e igarapés na Bacia Amazônica e nas áreas adjacentes. Parte I: Trecho Cuiabá-Porto Velho-Manaus. Acta Amazonica, 10(3):611-633.

LEENTVAAR, $P$.

1966 - The Brokoponcio lake in Surinam. Verh. Internat. Verein Limnol., 16:680-684.

1967 - The artificial Brokopondo Lake of the Surinam river, its biological implications. Atas do Simpósio sobre a Biota Amazônica, 3 (Limnologia):127-140.

1971 - Lake Brokopondo. Symposium on man-made lakes, Knoxville, USA, 36:1-22.

1973 - Lake Brokopondo. In: Ackermann, W.C.; White, G.F. \& Worthington, E.B. (eds.) Man-Made lakes. Their problems and environmental effects. Washington, Ameri. can Geophysical Union. p. 186-196.

LELEK, A, \& EL-ZARKAS, S.

1973 - Ecological comparison of the preimpoundment fish faunas of river Niger and Kainj: lake, Nigeria. In: Ackermann, W.C.; White, G.F. \& Wortington, E.B. (eds.) - Man-made lakes. Their problems and environmental effects. Washington American Geophysical Union. 655-660.

MARLIER G.

1965 - Etude sur les lacs de l'Amazonie Centrale. Cadernos da Amazônia, 5:1-55.

1967 - Ecological studies on some lakes of the Amazon valley. Amazoniana, 1(2):91-115.

1969 - Les eaux de I'Amazoníe, Les naturalistes Belges, 50(10):541-563.
MATSUMURA-TUNDISI, T.

1972 - Aspectos ecológicos de zooplâncton da regiảo lagunar de Cananéia com especial re. ferências aos Copepodas (Crustacea). São Paulo. 191 p. Tese de Doutoramento

PANTULU, V.R.

1975 - Environmental aspects of river development in Tropical Asia with particular reference to the Mekon Basin - Proceedings Second World Congress, International Water Resources Association, New Delhi, 5:349-360.

PETR, T.

1975 - On some factors associated with the initial high catches in New African man-macie lakes. Archiv. für Hydrobiologie, 75:32-49.

REISS, F.

1976 - Die Benthoszoozönosen zentralamazonischer Vársea-Seen und ihre Anpassungen an die jahresperiodischen Wasserstandscha wankungen. Biogeographica, 7:125-135.

1975 - Charakterisierung zentralamazonischer Seen aufgrund ihrer Makrobenthosfauna. Amazoniana, 6(1):123-134.

1977 - Qualitative and quantitative investigations on the macrobenthic fauna of Central Amazon Lakes. I. Lago Tupé, a black water lake on the lower Rio Negro. Amazoniana, $6(2): 203-235$.

RZOSKA, J.

1966 - Observations on zooplankton distribution in a tropical river dam-basin. (Gebel Aulyia, White Nile, Sudan). J. Animal Ecol., 37: 185-198.

SANTOS, D.B.; FERNANDES, P.E.C.A.; DREHER, A.M ;

CUNHA, F.M.B.; BASEI, M.A.S. \& TEIXEIRA, J.B.S. 1966 - Folha SB. 21 Tapajós, Geologia, In: Bra. sil. Departamento Nacional da Produção Mineral. Projeto RADAM: Folha SB. 21 Tapajós. Rio de Janeiro. $418 \mathrm{p}$.

SARS $G$.

1901 - Contributions to the knowledge of the freshwater Entomostraca of South America as shown by artificial hatching from dried material. Archiv for Mathematik og Naturvidenskab. 23(3):1-97.

SCHMIDT, G.W

1969 - Vertical distribution of bacteria and algae in a tropical lake. In. Revue geso Hydrobiol., 54(5):791-797.

SCHMIDT, G.W.

1972 - Amounts of suspended solids and dissolved substances in the middle reaches of the Amazon over the course of one year (August 1969 - July 1970). Amazoniana, 3(2):208-223.

1973 - Primary production of phytoplankton in the three types of Amazonian waters. I. Introduction. Amazoniana, 4(2):135-138. 
1973 - Primary production of phytoplankton in the three types of Amazon waters. II. The limnology of a tropical flood-plain lake in central Amazonia (Lago do Castanho). Amazoniana, 4(2):138-203.

1973 - Primary production of phytoplankton in the three types of Amazonian waters. III. Primary productivity of phytoplankton in a tropical flood-plain lake of Central Amazonia, Lago do Castanho, Amazonas, Brasil. Amazoniana, 4(4):379-404.

1976 - Primary production of phytoplankton in the three types of Amazonian waters. IV. On the primary productivity of phytoplankton in a bay of the lower Rio Negro (Amazo. nas, Brazil). Amazoniana, 5(4):517-528.

SIDTHIMUNKA, A.; BOONSOM, M.P.C. \&

PAWAPOOTANON, 0.

1968 - Observations on the hydrology and fisheries of Ubolratana Reservoir (1965-1966). Indo Pac. Fish. Council Publ. c/68/TECFiS:1-18.

SIOLI, H.

1957 - Valores de pH de águas amazônicas. Bol. Mus. Paraense Emílio Goeldi, 1:1-37.
1965 - A limnologia e a sua importância em pesquisas da Amazônia. Amazoniana, 1(1): 11-35.

1967 - Studies in Amazonian waters. Atas do Simpósio sobre a Biota Amazônica, 3(Limnnlogia) : 9-50.

1968 - Hydrochemistry and geology in the Brazilian Amazon region. Amazoniana, 1(3): 267-277.

1976 - A limnologia na região amazônica brasilei. ra. In: Anais do 1.॰ Encontro Nacional sobre Limnologia, Piscicultura e Pesca Continental, Belo Horizonte, 1975. Fundação João Pinheiro. p. 153-169.

SORENSEN, $T$.

1948 - A method of establishing groups of equal amplitude in plant sociology based on similarity of species content. Det Kongelige Danske Videnskabernes Selskab, Biolo. giske Skrifter, 4:1-34.

STRICKLAND, J.D.H. \& PARSONS, T.R.

1960 - A manual of sea water analyses. Ottawa, Fisheries Research Board of Canada.

(Aceito para publicação em 02/09/81 


\begin{tabular}{|c|c|c|c|c|c|c|c|c|c|c|c|c|c|c|c|c|c|c|}
\hline \multirow[t]{2}{*}{ FAMILIA/ } & \multirow{2}{*}{ Espécie } & \multicolumn{2}{|c|}{ Estação I } & \multicolumn{2}{|c|}{ Estação II } & \multicolumn{2}{|c|}{ Estação IV } & \multicolumn{2}{|c|}{ Estação V } & \multicolumn{2}{|c|}{ Estação VI } & \multicolumn{2}{|c|}{ Estaçạ̃o VII } & \multicolumn{2}{|c|}{ Estação Vill } & \multicolumn{3}{|c|}{$\begin{array}{c}\text { Total capturado p/ } \\
\text { espécie }\end{array}$} \\
\hline & & $\mathbf{R}$ & 1 & $\mathbf{R}$ & $\mathbf{I}$ & $\mathbf{R}$ & I & $\mathbf{R}$ & 1 & $\mathbf{R}$ & 1 & $\mathbf{R}$ & I & $\mathbf{R}$ & I & $\mathbf{R}$ & 1 & $\begin{array}{c}T \\
\end{array}$ \\
\hline
\end{tabular}

\section{CLUPEIDAE}

Peliona castelnean

Pellona flavipinnis

ERYTHRINIDAE

Hoplias malabaricus

Hoplias $\mathrm{sp}$

CTENOLUCIIDAE

Boulengerella maculata

ANOSTONIIDAE

Anostomus taeniatus

Anostomus trinfaculatus

Leporinus agassizi

Leporinus fasciatus

Leporinus friderici

Rhytiodus argenteofuscus

HEMIODIDAE

Hemiodopsis sp

Hemiodus unimaculatus

CURIMATIDAE

Curimata cyprinoides

Curimata vittata

Semaprochilodus theraponura

SERRASALMIDAE

Catoprion mento

Metynnis lippincottianus

Myleus pacu

Myleus schomburgki

Myleus sp (A)

Myleus sp (C)

Mylossoma duriventre

Serrasalmus rhombeus

Serrasalmus serrulatus

Serrasalmus striolatus

CHARACIDAE

Acestrorhynchus falcatus

Acestrorhyrichus falcirostris

Acestrorhynchus microlepis

Astyanax $\mathrm{sp}$

Brycon of pellegrini

Bryconops alburnoides

Bryconops gracilis

Bryconops melanurus

Chans erthrurus

Chalceus macrolepidotus

Charax pauciradiatus

Cynopotamus amazonus

Hydrolycus scomberoides

Moenkhausia justae

Tetragonopterus chalceus

Triportheus elongatus

RHAMPHICHTHYIDAE

Rhamphichthys rostratus

AUCHENIPTERIDAE

Auchenipterichthys $\mathrm{sp}$

Auchenipterus nuchalis

Centromochlus heckelii

Parauchenipterus galeatus

Tatia sp

PIMELODIDAE

Platynematichthys $\mathrm{sp}$

AGENEIOSIDAE

Ageneiosus brevifilis

Ageneiosus sp (A)

Ageneiosus $\mathrm{sp}(\mathrm{B})$

LORICARIIDAE

Hypoptopoma $\mathrm{sp}$
Plecostomus cf varimaculosus

CICHLIDAE

Cichla ocellaris

Cichla temensis

Cichlasoma cf crassa

Gichlasoma severum

Crenicichla of cincta

Crenicichla strigata

Geophagus surinamensis

Capturas por estação

Esforço total de pesca (horas)

Quantidade de malhadeiras

utllizadas

Total de espécies capturadas





\begin{tabular}{lll|l|l|l|l|l|l|l|l|l|l|l|l|l|}
- & - & 2 & 3 & - & 1 & - & - & 1 & - & 1 & - & - & - & 4 & 4
\end{tabular}

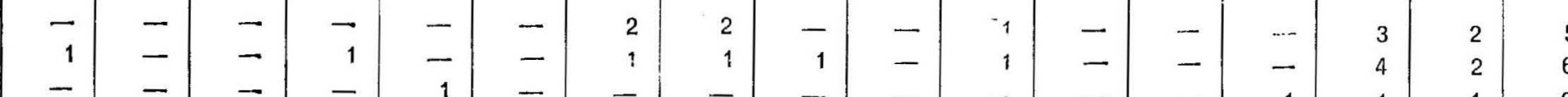

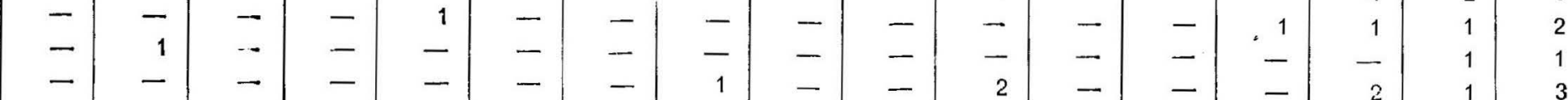

